\title{
Is human face recognition lateralized to the right hemisphere due to neural competition with left-lateralized visual word recognition? A critical review
}

\author{
Bruno Rossion ${ }^{1,2}$ (D) Aliette Lochy ${ }^{3}$ (D)
}

Received: 16 February 2021 / Accepted: 23 August 2021

○ The Author(s), under exclusive licence to Springer-Verlag GmbH Germany, part of Springer Nature 2021

\begin{abstract}
The right hemispheric lateralization of face recognition, which is well documented and appears to be specific to the human species, remains a scientific mystery. According to a long-standing view, the evolution of language, which is typically substantiated in the left hemisphere, competes with the cortical space in that hemisphere available for visuospatial processes, including face recognition. Over the last decade, a specific hypothesis derived from this view according to which neural competition in the left ventral occipito-temporal cortex with selective representations of letter strings causes right hemispheric lateralization of face recognition, has generated considerable interest and research in the scientific community. Here, a systematic review of studies performed in various populations (infants, children, literate and illiterate adults, left-handed adults) and methodologies (behavior, lesion studies, (intra)electroencephalography, neuroimaging) offers little if any support for this reading lateralized neural competition hypothesis. Specifically, right-lateralized face-selective neural activity already emerges at a few months of age, well before reading acquisition. Moreover, consistent evidence of face recognition performance and its right hemispheric lateralization being modulated by literacy level during development or at adulthood is lacking. Given the absence of solid alternative hypotheses and the key role of neural competition in the sensory-motor cortices for selectivity of representations, learning, and plasticity, a revised language-related neural competition hypothesis for the right hemispheric lateralization of face recognition should be further explored in future research, albeit with substantial conceptual clarification and advances in methodological rigor.
\end{abstract}

Keywords Neural competition $\cdot$ Faces $\cdot$ Words $\cdot$ FFA $\cdot$ VWFA

\section{The right hemispheric lateralization of human face recognition}

Face recognition, defined here as the reliable production of selective responses to faces, ${ }^{1}$ is extremely important for social interactions in the human species. We rely on facial cues to readily and automatically recognize, and sometimes act upon, someone's emotion, direction of attention through eye gaze and head orientation, gender, age, ethnical origin and identity, as well as to make social judgments of, e.g., dominance, attractiveness and trustworthiness (Bruce and

Bruno Rossion

bruno.rossion@univ-lorraine.fr

1 Université de Lorraine, CNRS, CRAN, 54000 Nancy, France

2 CHRU-Nancy, Service de Neurologie, 54000 Nancy, France

3 Université du Luxembourg, Esch-sur-Alzette, Luxembourg
Young 1998; Perrett 2012; Todorov 2017). This facial recognition ability evolves during development without formal training (i.e., it is a naturally developed ability) and ultimately constitutes what is arguably the richest (visual) recognition function in neurotypical human adults.

The dominance of the right hemisphere (RH) in human face recognition was initially evidenced by lesion studies, showing that prosopagnosia, a category-selective

\footnotetext{
${ }^{1}$ In psychology, the term "recognition" is often used to refer to the judgment of previous occurrence (specifically "the ability to identify information as having been encountered before", APA Dictionary of Psychology; see also Mandler 1980). In psychological research on human faces, the term is even often restricted to the judgment of a previous occurrence of specific identities of faces (i.e., familiar faces). Here it is used in a more general biological sense as the reliable production of selective (i.e., differential) responses to sensory inputs at different levels, ranging from the recognition of a visual stimulus as a face ("generic face recognition") to its specific identity ("face identity recognition") or its emotional expression ("emotional facial expression recognition").
} 

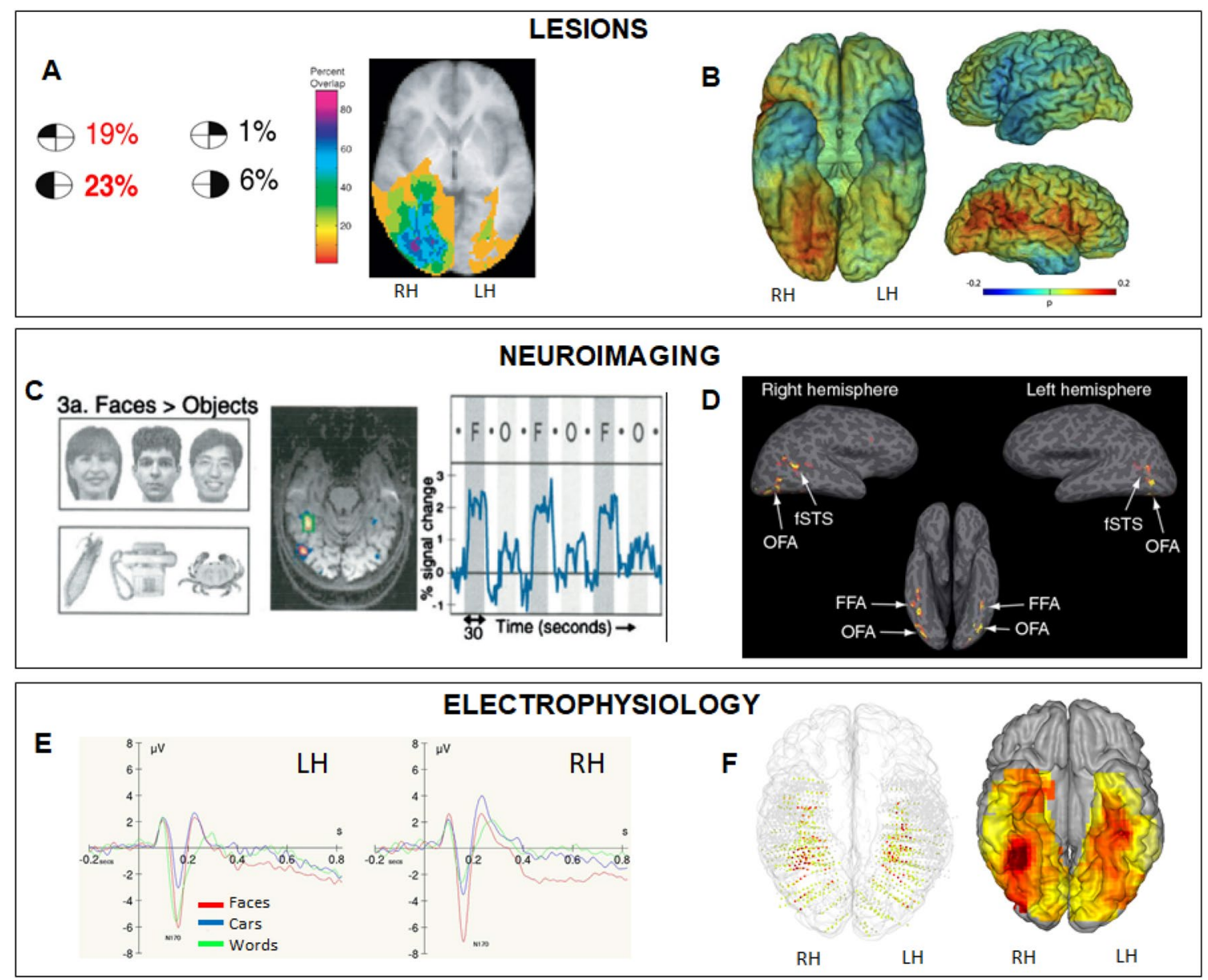

Fig. 1 Various illustrations of the RH dominance in human face recognition, with lesions studies (A, B), neuroimaging (C, D) and electrophysiology $(\mathbf{E}, \mathbf{F})$. A Left: there is a higher percentage of patients with prosopagnosia associated with left as compared to right visual field defects (19 vs. $1 \%$ in the upper visual field; 23 vs. $6 \%$ in both the upper and lower visual fields), indicating predominant lesions in the right as compared to the left VOTC (original observation by Hecaen and Angelergues 1962; here from the sample of Bouvier and Engel 2006); Right: overlap of lesions causing prosopagnosia, from Bouvier and Engel 2006; see also Cohen et al. 2019). B Probability maps associated with deficits at matching pictures of unfamiliar faces in a classical neuropsychological test (201 brain-damaged participants; Tranel et al. 2009; Positive (negative) values in the color bar indicate a greater (lower) proportion of participants with a lesion and a deficit among those with a deficit. Note the larger involvement of right as compared to left VOTC structures, but also for the lateral

neurological deficit of face identity recognition (FIR) (Bodamer 1947; see Rossion 2018a for a recent review) was most commonly associated with left upper visual field defects, typical of a right ventral occipito-temporal lesion (Hécaen and Angelergues 1962; Meadows 1974; Bouvier and Engel 2006; Fig. 1A). Although bilateral lesions are most commonly observed in cases of prosopagnosia (Damasio et al. 1982), damage to the RH is necessary, and can be sufficient, to cause the impairment (e.g., Landis et al. 1986; De Renzi occipito-temporo-parietal junction around the posterior temporal sulcus. C Face-selective responses in fMRI are larger in the RH than the LH. Illustration of the so-called "Fusiform Face Area" (FFA), from Kanwisher et al. 1997, usually identified by comparing blocks of face stimuli (F) to object (O) stimuli. D Illustration of the network of faceselective regions in the VOTC and superior temporal sulcus (STS), from Kanwisher and Yovel (2006). E ERP findings illustrating the larger N170 amplitude in the RH for faces and in the LH for written words. Hemispheric asymmetry is not observed for pictures of cars (from Rossion et al. 2003). F Mapping of selective responses to faces measured with a frequency-tagging approach in intracerebral recordings in a large sample of individuals, showing a larger amplitude (red color) to faces in the $\mathrm{RH}$, in particular the right lateral section of the middle fusiform gyrus (from Jonas et al. 2016; see also Hagen et al. 2020)

et al. 1991; Sergent and Signoret 1992; Bouvier and Engel 2006; Barton 2008; Cohen et al. 2019). Besides these rare cases of prosopagnosia, ${ }^{2}$ group studies of brain-damaged

\footnotetext{
2 The definition of prosopagnosia used here does not include cases of developmental disorders at FIR in the absence of neurological history, which are often referred to as developmental prosopagnosia or congenital prosopagnosia (Behrmann and Avidan 2005; Duchaine and Nakayama 2006), but more correctly as prosopdysgnosia (Rossion 2018b; Sorensen and Overgaard 2018).
} 
patients have generally shown that lesions in the posterior region of the RH often disrupt FIR (as typically tested with tasks requiring the discrimination and matching of unfamiliar faces for their identity), while a similar lesion in the left hemisphere (LH) usually leaves this function intact (Benton and Van Allen 1968; De Renzi 1986; Newcombe et al. 1989; Tranel et al. 2009; Fig. 1A, B). Following lesion studies, behavioral experiments performed in neurotypical individuals with lateralized visual stimulation, including chimeric stimuli made of two left or right halves of the same face identity, have also shown RH advantage in FIR (Rizzolatti et al. 1971; Levy et al. 1972; Gilbert and Bakan 1973; Kolb et al. 1983; Hillger and Koenig 1991; Yovel et al. 2003; Brederoo et al. 2020).

From the 1990s, functional neuroimaging (initially positron emission tomography, PET; then functional magnetic resonance imaging, fMRI) studies of the human brain revealed bilateral occipito-temporal activity, with a larger amplitude in the RH than $\mathrm{LH}$, to the presentation of face stimuli and to the difference in signal between faces and other visual forms (i.e., face-selective responses; Sergent et al. 1992; Puce et al. 1996; Kanwisher et al. 1997; McCarthy et al. 1997; for more recent studies: Rossion et al. 2012; Zhen et al. 2015; Frassle et al. 2016; see also Yovel et al. 2008 for a link between behavioral and neural right hemispheric dominance) (Fig. 1C, D).

Initial electroencephalographic (EEG) studies did not report RH advantage of selective event-related potentials (ERPs) to faces (Bötzel and Grüsser 1989; Jeffreys 1989; although see Srebro 1985), probably for methodological reasons (e.g., linked mastoid references, lack of low temporal electrodes and a focus on central electrodes for analysis; see Joyce and Rossion 2005). However, subsequent ERP studies consistently identified a face-selective occipito-temporal potential, the N170, which is generally larger in the RH than LH (Bentin et al. 1996; for review: Rossion and Jacques 2011) (Fig. 1E). More recently, electrophysiological studies using fast periodic visual stimulation (frequency-tagging, ${ }^{3}$ ) have objectively isolated and quantified face-selective responses (Rossion et al. 2015) or FIR responses (Liu-Shuang et al. 2014; Rossion et al. 2020) in the EEG frequency domain, systematically showing a right

\footnotetext{
${ }^{3}$ Fast periodic visual stimulation or "frequency-tagging" in EEG is a technique in which stimuli are presented at a (usually fast) periodic rate, leading to neural responses expressed in the EEG frequency spectrum (Regan 1966). This technique has considerable advantages in terms of sensitivity and objectivity of measurement (see Norcia et al. 2015; Rossion et al. 2020 for reviews).
}

hemispheric advantage in terms of amplitude over occipitotemporal brain regions.

In the same vein, initial intracranial, electrophysiological, low-frequency-band responses ("local field potentials") to faces in patients with epilepsy refractory to medication were also described in occipito-temporal regions of both hemispheres, without any report of hemispheric lateralization (Allison et al. 1994; Halgren et al. 1994; see also e.g., Vidal et al. 2010 for bilateral face-selective broadband high frequency 'gamma' activity). However, more recent intracranial recordings of large samples of individual brains with a frequency-tagging approach have also now demonstrated larger face-selective responses in the right as compared to the left ventral occipito-temporal cortex (VOTC) (Jonas et al. 2016; Hagen et al. 2020; Jacques et al. 2020) (Fig. 1F). Finally, causal studies with transcranial magnetic stimulation (TMS) (Pitcher et al. 2007) and especially intracranial electrical stimulation (Jonas et al. 2012; Rangarajan et al. 2014) have corroborated the RH dominance of face recognition. Strikingly, up till now, cases of transient impairment in FIR following intracerebral electrical stimulation have been observed in various VOTC regions, but only in the RH (Jonas and Rossion 2021).

According to this brief summary, decades of observations across a wide variety of methodologies have provided overwhelming evidence for the RH advantage in (category-selective) response to faces, or to FIR measures, in the human adult brain. In some studies, this RH lateralization has been quantified, showing for instance a 2.3-fold increase of faceselective amplitude in intracerebral recordings of the lateral section of the middle fusiform gyrus of the RH as compared to the LH (Jonas et al. 2016; Fig. 1F).

Despite the long-standing scientific interest in hemispheric lateralization of function (Broca 1865; Gazzaniga 1967; Geschwind and Levitsky 1968; Bradshaw and Nettleton 1981) and the biological and social importance of face recognition for humans, the factors driving the $\mathrm{RH}$ lateralization of this latter function remain largely mysterious. In the present review, we focus specifically on a current, influential hypothesis according to which the RH lateralization of face recognition is due to neural competition in the left hemisphere with the representation ${ }^{4}$ of letter strings (Behrmann and Plaut 2015, 2020; Dehaene et al. 2010, 2015).

\footnotetext{
4 The term 'representation' as used here refers merely to (a pattern of) activity in the neural system that has a systematic relationship with a sensory stimulus of the environment. Although the term 'representation' has sometimes been used in neuroimaging in the restrictive context of multivariate pattern analysis (Kriegeskorte et al. 2008), the neural activity does not have to be distributed across spatial units such as voxels (e.g., larger neural activity to faces than non-face stimuli in the right lateral middle fusiform gyrus as a whole "represents" face stimuli).
} 
In the next section (Sect. 2), we briefly put this hypothesis in context and summarize the key principles upon which it rests. Next, evidence in favor or against this hypothesis is evaluated in depth (Sect. 3), before briefly discussing complementary or alternative views of RH lateralization of faces and directions for future research on this scientific issue (Sect. 4).

\section{Is human face recognition right-lateralized due to left language lateralization?}

Why is face recognition right-lateralized in the human brain? While various hypotheses have been advanced, usually in terms of dichotomies of preferential stimuli or processes between the LH and RH (e.g., verbal vs. pictorial; local vs. global; analytic vs. holistic; high vs. low spatial frequencies; coordinate $v s$. categorical spatial relationships, respectively; see Bradshaw and Nettleton 1981; also Sergent 1988; Farah 1990 and Sect. 3 of the present review), it has long been proposed that right-lateralized functions of the human brain, such as face recognition, occur merely as a consequence of the well-established LH lateralization of the language function (Lhermitte et al. 1972; Gazzaniga and Ledoux 1978; Corballis and Morgan 1978; Ellis 1983). For instance, LeDoux (1983) explicitly proposed that visuospatial skills in the occipito-temporo-parietal junction could be primarily mediated by brain areas of the right hemisphere because of the opposite left hemispheric region being taken over by language in humans (i.e., Wernicke's area). According to this view, many right hemispheric advantages, including face recognition, are mere consequences of invasion of the left hemisphere by language (and praxis) skills in humans (Ellis 1983; Corballis 1983, 1991; see also Gotts et al. 2013).

Regarding face recognition, this view appears to be supported at a general level by contrasting observations of $\mathrm{RH}$ lateralization between humans and other animal species, which are devoid of language. Indeed, while there are a few reports of RH lateralization in the behavioral processing of face stimuli in non-human animal species (e.g., in macaque monkeys: Hamilton and Vermeire 1983, 1988; Vermeire et al. 1998; in sheep: Peirce et al. 2001; in chimpanzees: Dahl et al. 2013), the data are weak and rather controversial (Overman and Doty 1982; Doty et al. 1999). Moreover, evidence for RH lateralization of face recognition at the neural level in non-human species is very weak (in sheep: Peirce and Kendrick 2002), contradictory (e.g., in macaques: Perrett et al. 1988 vs. Zangenehpour and Chaudhuri 2005) and more often non-existent (see also Chance et al. 2013, showing microstructural asymmetry in the middle fusiform gyrus of humans but not chimpanzees). In particular, the macaque monkey, widely considered in the neuroscientific community as the best available animal model to understand human visual recognition, including face recognition (DiCarlo and Cox 2007; but see Rossion and Taubert 2019), shows no sign of RH lateralization in terms of face-selective responses as recorded in fMRI (e.g., Tsao et al. 2008) or in neurophysiology (Perrett et al. 1988). As put forward already in an early review of RH lateralization of human face recognition “... this suggests that lower primates may be entirely bilateral in their processing of faces, and provide circumstantial evidence for the idea that any symmetry found in human subjects may have arisen as a result of language development in the dominant hemisphere. The evolution of a language processor situated usually in the left hemisphere may have reduced the available space in that hemisphere for processing visuospatial information, including faces" (Ellis 1983, p. 58).

Building upon these initial views, a more specific language-related hypothesis has been advanced over the last decade regarding the RH lateralization of human face recognition: that it is due to neural competition with the selective visual representation of letters and words in the $\mathrm{LH}$, in particular in the left VOTC (Dehaene et al. 2010, 2015; Behrmann and Plaut 2015, 2020). That is, during reading acquisition, populations of neurons in the left VOTC, essentially in the left middle fusiform gyrus, would become selective to letter strings, ${ }^{5}$ because of spatial constraints due to proximity with other language functions in the left hemisphere in the majority of humans (Posner and Carr 1992; Jacobs and Jordan 1992; Behrmann and Plaut 2015), preferential connectivity to language-related structures (Saygin et al. 2016; Stevens et al. 2017; Bouhali et al. 2014; Li et al. 2020; Hannagan et al. 2015; Lerma-Usabiaga et al. 2018; Ekstrand et al. 2020; Bedny 2017), high-resolution foveal representation (Hasson et al. 2002; Gomez et al. 2018), and/or because of initial tuning of this brain tissue for sensitivity to line junctions and high spatial frequencies ${ }^{6}$ (Szwed et al. 2011). Due to competition for cortical space, selectivity to faces initially supported by both left and right homologous VOTC regions, would be reduced in the $\mathrm{LH}$, therefore relying increasingly on RH structures (Dehaene et al. 2010; Behrmann and Plaut 2020). Hence, reading acquisition would

\footnotetext{
5 In the remainder of the text, we will typically use the term 'letter strings' as a general term that encompasses words (e.g., familiar written forms), non-words (unmeaningful strings of letters), or even consonant strings. The distinction is relevant given the debate of whether the visual word form area (VWFA) processes only pre-lexical (McCandliss et al. 2003) or also lexical representations (Glezer et al. 2009, 2015; Kronbichler et al. 2004).

${ }^{6}$ Note that the spatial frequency hypothesis is not supported by training studies on reading acquisition with atypical visual shapes (such as faces or houses) differing greatly from the natural script characteristics, but also revealing the left middle fusiform gyrus as the site of learning effects (Moore et al. 2014; Hirshorn et al. 2016; Martin et al. 2019).
} 
directly cause RH lateralization for faces. Here, we will refer to this hypothesis as the reading-induced Lateralized Neural Competition hypothesis (the reading-LNC hereafter).

Besides the long-standing language-related view for a right hemispheric advantage in non-language functions including face recognition (Gazzaniga and LeDoux 1978; Corballis and Morgan 1978; Ellis 1983; Corballis 1991) and empirical evidence from experiments that have been designed to test it specifically (as reviewed in the next section), this currently influential reading-LNC hypothesis, according to which right hemispheric lateralization for face recognition would have emerged only over the past thousands of years in Homo sapiens, rests on four key principles. First, the well-established evidence that, in line with the language function in general, the LH is dominant in visual recognition of letters and words in most adult individuals (Gazzaniga et al. 1965; Newcombe et al. 1989; Rizzolatti et al. 1971; Farah 1990; early neuroimaging evidence: Petersen et al. 1988; Puce et al. 1996; EEG: Salmelin et al. 1996; Tarkiainen et al. 1999; Rossion et al. 2003; lesion studies: Déjerine 1891; Hillis et al. 2001; Hillis et al. 2005; but see Olulade et al. 2020 for fluctuations of hemispheric lateralization of language during development). Second, the relatively more recent definition of neighboring category-selective representations of visual letter strings and faces in the adult VOTC, in particular in the middle fusiform gyrus of the LH, where a brain region responding selectively to letter strings, the so-called Visual Word Form Area (VWFA) is found in the vicinity of the left FFA (usually slightly laterally; Cohen et al. 2002; Cohen and Dehaene 2004; McCandliss et al. 2003; Kronbichler et al. 2004; Devlin et al. 2006; DaviesThompson et al. 2016; Kubota et al. 2019) (Fig. 2). Third, that face and visual word recognition would share important functional characteristics, such as the requirement of high-resolution foveal representations (Hasson et al. 2002) as well as both part-based and holistic representations (e.g., Martelli et al. 2005; Wong et al. 2019). Fourth and finally, neural competition as a general principle of brain function, namely the view that sensory inputs (or motor outputs) sharing functional characteristics compete for the same populations of neurons in the cerebral cortex (Edelman and Finkel 1985; Edelman 1987), this competition being mediated by synaptic excitation and inhibition, and forming the basis of selectivity, learning and cortical plasticity (Merzenich et al. 1988; Zhang et al. 2003).

\section{A systematic evaluation of the lateralized neural competition hypothesis}

The main prediction of the reading-LNC hypothesis is that there is a causal, unidirectional, link between LH lateralization for letter strings in the VOTC and RH lateralization for faces (Dehaene et al. 2010, 2015; Behrmann and Plaut $2015,2020)$. That is, RH lateralization for faces would emerge because of the LH specialization for letter strings in the VOTC, and would be further modulated during development and across the lifetime by reading acquisition and improvement.

A secondary prediction is that face recognition would change with letter-string selectivity. On the one hand, this change would be expressed at a quantitative level, i.e., a diminution in performance. Specifically, the ability to recognize letter strings (literacy) would cause "small losses in perceptual and cognitive abilities due to competition of the new cultural ability with the evolutionarily older function in relevant cortical regions" (Dehaene and Cohen 2007). On the other hand, under the view that the right and left hemispheres differ in terms of the types of processes/representations involved in visual recognition (e.g., holistic vs. analytic, respectively; de Moraes et al. 2014; Farah 1990; Ivry and Robertson 1998; Sergent 1982a, b), there should be a qualitative alteration of face recognition (e.g., increase in holistic representation).

Below, we evaluate the data supporting the first prediction (RH shift of face recognition) and the second prediction in turn.

\section{Does letter-selectivity in the left hemisphere cause the right lateralization of face-selective responses?}

\section{Impact of variable literacy levels at adulthood}

At the root of the reading-LNC hypothesis, an influential fMRI study compared groups of Portuguese and Brazilian illiterate adults, ex-illiterate (who learnt to read at adulthood) and literate adults, reporting a larger LH specialization for letter strings in the left fusiform gyrus with increasing levels of literacy (Dehaene et al. 2010). Since this effect was accompanied by a relatively smaller response to faces in the same region in literates (Dehaene et al. 2010), the headline of that study, which has generated substantial experimental studies and reviews, was that "the gain of function appeared to occur at a cost- the area in the temporal cortex devoted to face processing shrank" (Dehaene et al. 2010) ${ }^{7}$. Critically, a relatively larger response to faces was also reported in the RH in literates compared to illiterates (Dehaene et al. 2010), providing apparent support for the hypothesis evaluated in the present review.

While literacy undoubtedly causes profound changes in brain structure and connectivity beyond neural responses to print (Castro-Caldas et al. 1999; Carreiras et al. 2009; Skeide et al. 2017; Thiebaut De Schotten et al. 2014) and

\footnotetext{
$\overline{7}$ https://science.sciencemag.org/content/330/6009/1359.
} 
A

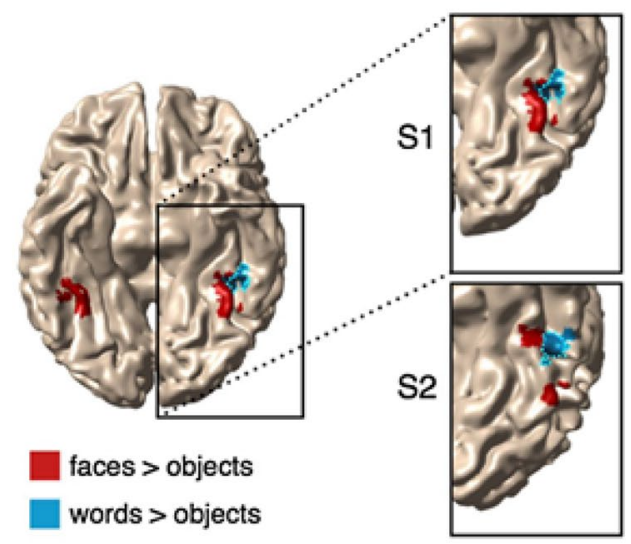

B
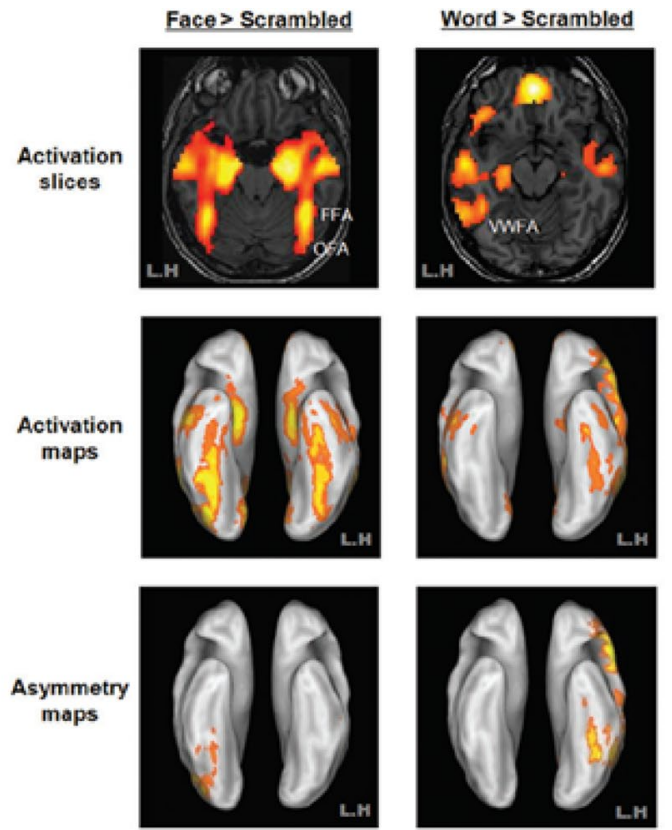

C
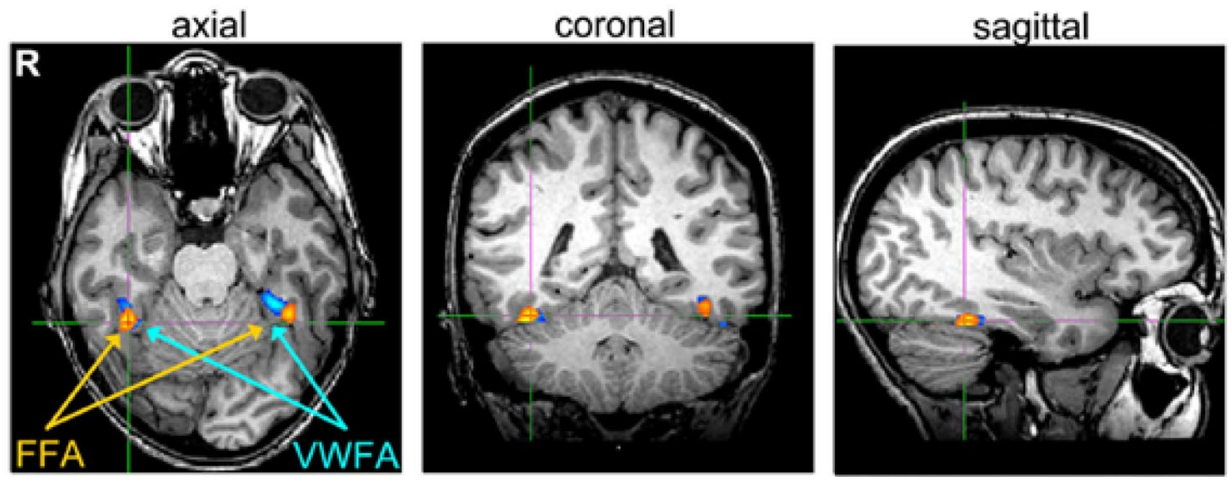

Fig. 2 Illustration of the respective localizations of the VWFA and FFA in fMRI. A Selective responses to faces and written words in Kubota et al. (2019), showing a slightly more lateral selective response to written words than faces in the middle fusiform gyrus; B Brain regions responding to faces and words against scrambled stimuli are represented as activation slices (top row), projected on

may enhance early visual responses to non-linguistic stimuli (Pegado et al. 2014a, b), a careful analysis indicates that the right hemispheric shift of neural face representation claimed in the fMRI study of Dehaene et al. (2010) does not rest on solid evidence. First, as the authors themselves acknowledged, the lower response to faces in literates induced by the expansion of orthographic representations in the left fusiform gyrus was 'small' (abstract) or 'modest' (p. 1361), given that the results of the regression with reading performance (assessed by the number of words read per minute) measured independently was actually marginal (Dehaene et al. 2010). Second, this decrease did not occur at the peak of the FFA but only on the weakest face-selective voxels an inflated brain (middle row), with an illustration of the asymmetry between hemispheres in the bottom row (from Pinel et al. 2015). C Axial, coronal and sagittal views of regions responsive to words and faces in a single individual (against their scrambled control stimuli) in Davies-Thompson et al. (2016)

at the edge of the region (e.g., a 6-8 voxel radius). Third, the decrease was not specific to faces: it was also observed for another type of stimuli, houses (Dehaene et al. 2010, Fig. S6 of the study). Fourth, the decrease of response to faces in the LH was unrelated to reading performance (e.g., besides illiterates, a group of ex-illiterates with the lowest reading performance had the lowest response to faces in the left fusiform (VWFA); Dehaene et al. 2010; Fig. 3 and Fig. S2 of that study; see Fig. 3 below).

Finally, and perhaps most importantly, as also acknowleged by the authors, the relative increase in the RH (shown by positive correlations between reading scores and $\mathrm{RH}$ responses) was not specific to faces (i.e., occurred also for 

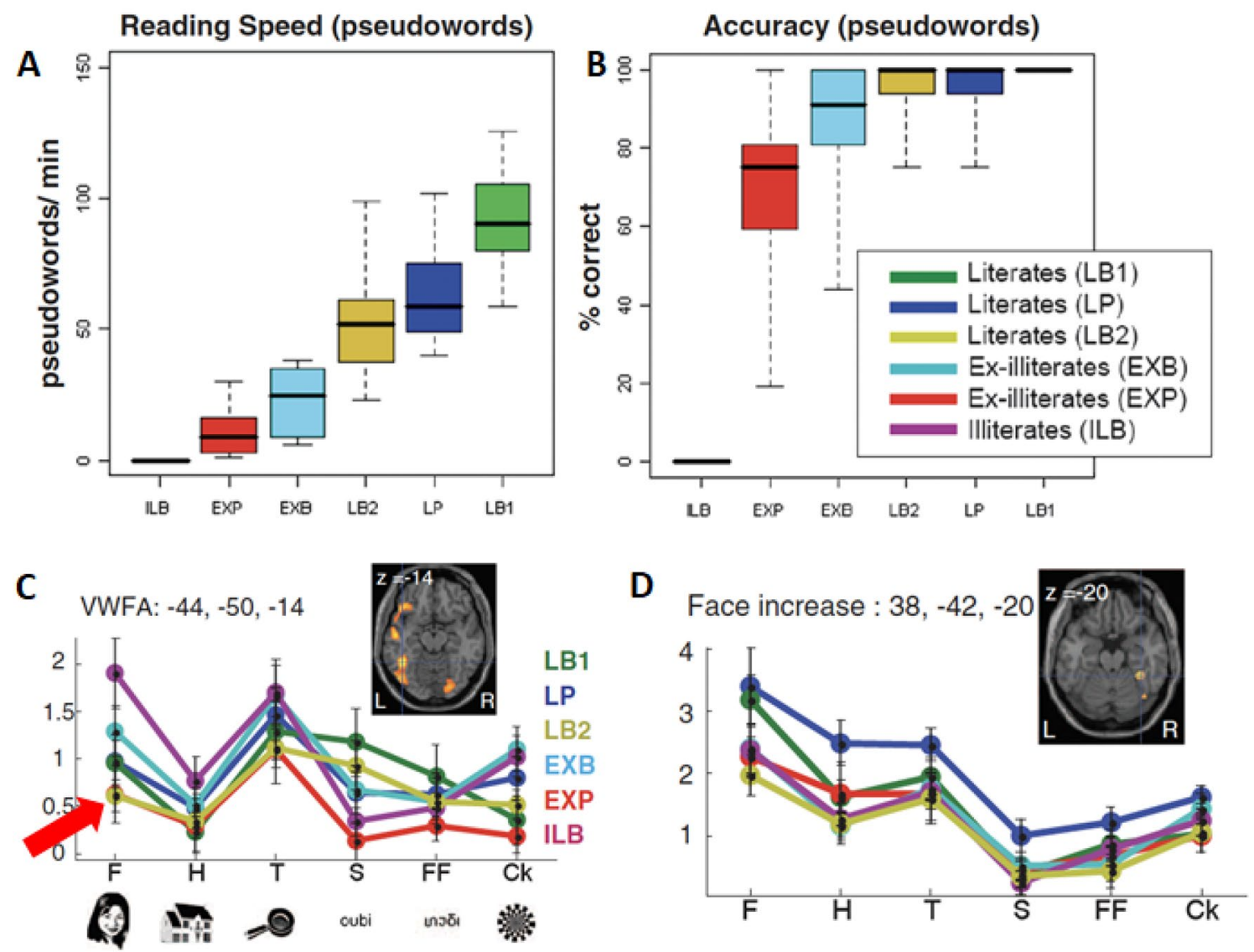

Fig. 3 (Adapted from Dehaene et al. 2010). Above A, B: reading performance of the six groups of participants (Literates are from Brazil (LB) or Portugal (LP), differentiated according to their socio-economic status: LB1 are not matched while LB2 are matched to Illiterates (ILB). Ex-illiterates (EX) who learned to read at adulthood and are distinguished per country (B or P). Illiterates (ILL) are all from Brazil; see also supplementary material S1 of the original study). Note the relatively low performance of Portuguese ex-illiterates (EXP) who, accordingly, also had the lowest neural response to letter strings (S) and false fonts (FF) in the defined left VWFA (in $\mathbf{C}$ ).

houses) and was related to the type of living neighborhood (rural/urban) rather than to literacy: "Notably, however, face and houseincreases were found neither when we compared illiterates with their socio-economic status-matched literate group" (Fig. 3) (Dehaene et al. 2010, p. 1362). This finding is in line with subsequent evidence that being exposed to larger hometowns population size affects not only performance in face-learning tasks (Balas and Saville 2017) but also face-selectivity of the N170 (Balas and Saville 2015), thereby showing the influence of experience with faces — rather than literacy—on behavioral and neural face recognition.

In summary, a careful look at the study of Dehaene et al. (2010), which included only 10 complete illiterates with important differences in their demographic characteristics or attempts to attend alphabetization classes (Huettig and

Despite this, their response to faces was among the lowest in this region (see also supplementary Fig S2. of the original study), against the hypothesis of reading-induced lateralized neural competition. D The increase to faces in the right hemisphere was found mainly in the right anterior fusiform gyrus, in a more anterior and medial region than the FFA, and essentially concerned participants living primarily in urban areas (in blue and green) regardless of their schooling and reading scores. Illiterates do not differ from the other three groups of literates tested

Mishra 2014) does not provide evidence that literacy causes a RH shift or increase of face-selective representation in the VOTC.

Subsequently, a smaller sample of the participants from the fMRI study was tested in EEG by Pegado et al. (2014a), also claiming for an an increase of RH lateralization for faces in proportion to the participants' reading ability. Despite this, the relationship between literacy and the faceselective N170 lateralization was non-significant (and in the opposite direction as predicted, $r=-0.07$ ) and there was no hemispheric difference on the amplitude of this component between literates and illiterates. Instead, the authors' conclusion was based a source space analysis of EEG data, showing a non-significant marginal increase of responses to faces with literacy in the RH $(r=0.23)$ at around $168 \mathrm{~ms}$ poststimulus onset, as well as a decrease in the LH $(r=-0.25)$, 
leading to a trend for a relationship between literacy scores and RH lateralization for faces $(r=-0.28)$ at this latency. However, literacy also led to a large enhancement for faces in the same localized region in the LH only at a later timecourse (Fig. 4 of Pegado et al. 2014a, b), and whether these effects were due to increased visual experience with faces rather than literacy as in Dehaene et al. (2010) was not evaluated. In line with these two studies, a longitudinal fMRI single-case study over the course of literacy acquisition (Braga et al. 2017) reported a slight decrease in face-selective responses near the VWFA site in the LH, but there was no correlation between time (i.e., reading improvement) and activation to faces in either of the two hemispheres, and no observable increase for faces in the RH.

Most recently, a recent large-scale fMRI study compared neural responses of illiterate/literate adults to letter strings and faces, reaching a different conclusion than Dehaene and colleagues (Hervais-Adelman et al. 2019). This latter study included 91 participants of different literacy backgrounds (31 of them being completely illiterate), finding no evidence for hemispheric displacement of selective responses to other categories (including faces). In contrast, while literacy enhanced responses in the left fusiform gyrus for letter strings, it also enhanced visual responses to other categories, including faces. In fact, literacy correlated significantly with increased left-lateralized responses to faces (HervaisAdelman et al. 2019). Admittedly, the acquisition of an alphasyllabic script in this study, which is more complex at the visuo-spatial level than the alphabetic script used in the studies of Dehaene et al. (2010) and Pegado et al. (2014a, b), may have played a role in these results (since responses to reading are more bilateral). However, while literacy indeed increased neural responses both in the left VWFA and its homolog region in the right hemisphere, correlation with literacy was significant only in the left hemisphere. Moreover, and importantly, there was no negative correlation between literacy and the extent of voxels responding to faces or other visual stimuli, thereby showing no shrinkage - and no displacement - of neural tissue responding to those other categories with reading acquisition.

Overall, we conclude from our critical evaluation of studies comparing literate and illiterate adults that they do not support the reading-LNC hypothesis of RH lateralization of face recognition.

\section{Infant studies}

While cognitive neuroscience studies contrasting illiterates to literates are very interesting, some illiterate adults have been exposed to print in specific contexts throughout lifetime (mainly in urban areas), potentially leading to (proto-) specialization of cortical responses for these stimuli. This is much more unlikely for young infants, who show sensitivity from birth to the general visual characteristics of face stimuli (Goren et al. 1975; Johnson et al. 1991; Turati and Simion 2002) and are intensely exposed to faces during the first months of life (Sugden et al. 2014). Therefore, a key question is whether there is evidence of RH lateralization for faces in infants, well before exposure to print and reading acquisition.

On the one hand, EEG studies using a standard eventrelated potential (ERP) approach have not reported hemispheric differences to face stimulation, or differences in responses to faces with other visual stimuli (cars, toy pictures), in infants of a few months old (de Haan and Nelson 1999; Gliga and Dehaene-Lambertz 2007). For instance, the N290 component evoked by faces and often considered to be a precursor of the adult N170, is associated with a medial occipital (rather than lateralized, occipito-temporal) scalp topography. In the same vein, a latter face-sensitive N400 component in infants is not lateralized (de Haan et al. 2003, for review). More recently, Deen et al. (2017) studied face and non-face stimuli in 4-6-month-old infants with fMRI, claiming to identify category-selective regions with a spatial organization similar to adults but with no hint of a RH lateralization for face stimuli. However, with the use of only a few uncontrolled (movie) stimuli in that study, no clear face-selective responses were recorded in the infant VOTC (possibly due to a low quality of fMRI signal, with only 9/22 infants displaying sufficient low-motion for inclusion in the analyses), making it not reliable enough to assess the question at stake.

On the other hand, against the prediction of the lateralized neural competition hypothesis, several observations relying on lateralized visual stimulation suggest that the RH lateralization for faces is already present in a few months old infants. For instance, 4-9 months of age children saccade faster towards their mother's face than a stranger's face when these pictures are presented in the left visual field (LVF) but not in the right visual field (RVF), and they also learn to recognize unfamiliar faces faster in the left than the right hemifield (de Schonen et al. 1986; de Schonen and Mathivet 1990). Also, in 1- to 5-month-old infants, new/deviant faces inserted in a stream of standard faces are discriminated (as attested by larger N290 and weaker N400 EEG amplitudes) only when face stimuli appear in the LVF (Adibpour et al. 2018; Fig. 4C). In line with these observations, early deprivation of visual input for several months (between 6 weeks and 3 years) to the right but not the left hemisphere causes atypical FIR at adulthood (Le Grand et al. 2003).

With neuroimaging, a positron emission tomography (PET) study of six 2- to 3-month-old infants looking at unknown female faces reported a significantly larger response to faces than a simple visual control stimulus in the right but not in the left middle fusiform gyrus (Tzourio-Mazoyer et al. 2002; Fig. 4A). Moreover, functional 
A

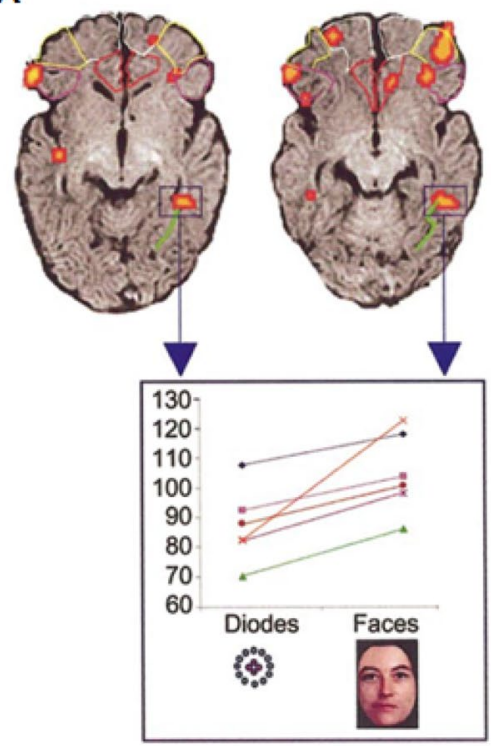

B

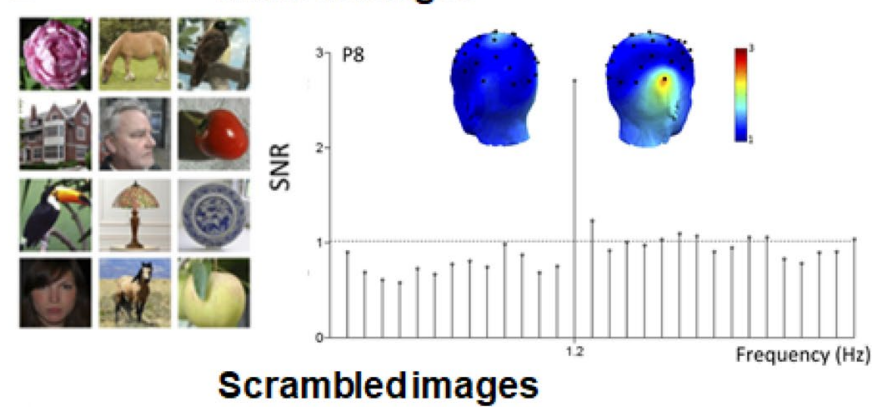

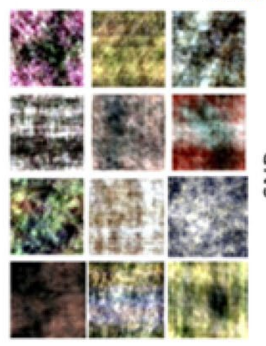

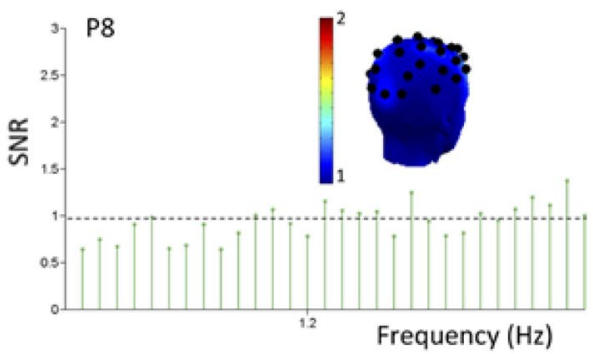

C

\section{Contralateral Face}

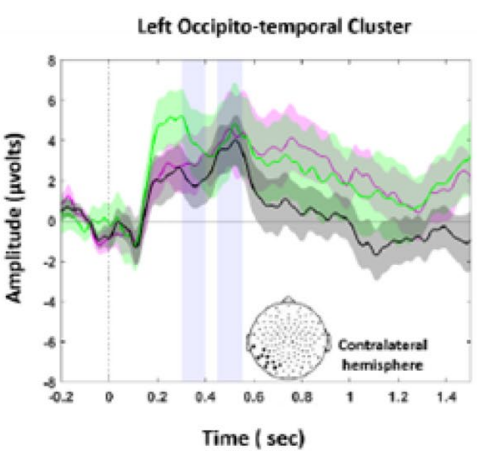

Fig. 4 A Results from Tzourio-Mazoyer et al. (2002). In a PETstudy, 2-3-month-old infants show greater responses to faces than simple control stimuli in the middle fusiform gyrus of the RH and not in the LH. B Results from the EEG study of de Heering and Rossion (2015). 4-6-month-old infants viewed 20 s sequences of stimulation where images were presented at $6 \mathrm{~Hz}$. Highly variable images of faces occurring every five stimuli generate a category-selective response at $1.2 \mathrm{~Hz}$ in the RH only. The EEG spectrum and 3D scalp topography of the frequency-tagged response for faces (i.e., generic face recognition) are displayed on the top panel (experiment 1 of the original study), a response that is not driven by low-level cues

near-infrared spectroscopy (fNIRS) studies have shown a significant RH advantage for faces over other visual stimuli in 5- to 8-month-old infants (e.g., Otsuka 2014; for review). Unfortunately, while these observations support the view that the RH lateralization for faces occurs at an early age, they are generally limited since they do not measure faceselective (i.e., differential) neural activity, or do so using inappropriately matched control stimuli (e.g., TzourioMazoyer et al. 2002; Fig. 4A).

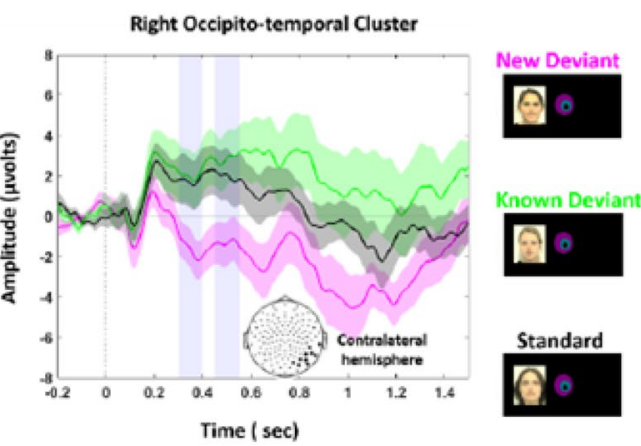

as shown by its absence (below) for phase-scrambled versions of the stimuli (experiment 2). Note that the $1.2 \mathrm{~Hz}$ response for natural images is already face-selective, with the common visual response to faces and non-face objects appearing at a $6-\mathrm{Hz}$ base rate frequency in the EEG spectrum over bilateral medial occipital sites (not shown here; see e.g., de Heering and Rossion 2015). C Results from Adibpour et al. (2018). In 2.5-5-month-old infants, ERP responses to the detection of a new deviant face presented in the contralateral hemifield generate an individual discrimination response only in the right hemisphere

In this context, the report of a face-selective EEG response predominantly over the right occipito-temporal cortex already at 4-6 months of age (de Heering and Rossion 2015; Fig. 4B) arguably constitutes the strongest evidence to date against the reading-induced lateralized neural competition hypothesis evaluated here. Indeed, thanks to the frequency-tagging approach used in that study (see also Fig. 5A, "Generic Face Recognition" sequence), the robust face-selective response is isolated from a common bilateral response to faces and objects. Moreover, the potential 
contribution of low-level visual cues as contained in the amplitude spectrum of the highly variable natural images is ruled out by the absence of face-selective response to phasescrambled versions of these images (Fig. 4B; de Heering and Rossion 2015). The strong right lateralization of the faceselective response over occipito-temporal channels obtained in 27 infants across two experiments in the original study has been replicated in three recent studies of 4 months old tested with a different stimulus set (Leleu et al. 2020; Rekow et al. 2020, 2021), providing consistent data in more than 100 infants tested in total. Importantly, in all these studies, the common neural activity to face and non-face objects that is frequency-tagged at a base rate of $6 \mathrm{~Hz}$ leads to a bilateral medial occipital response in infants, ruling out an alternative account of the RH lateralization of the face-selective response in terms of general advantage to all visual stimuli at that age due to, e.g., attentional factors or a spatial frequency bias (Behrmann and Plaut 2020).

Overall, even considering that hemispheric lateralization from EEG responses on the scalp cannot be inferred with certainty, ${ }^{8}$ the findings in infancy described above cast strong doubt on the view that human RH lateralization of face recognition is (initially) caused by neural competition with letter strings in the LH. However, providing that the $\mathrm{RH}$ lateralization of face-selective response in infancy is not permanent, they do not rule out a subsequent modulation of RH lateralization with active exposure to print (i.e., reading acquisition) at later stages of development. This issue is reviewed and discussed in the next section.

\section{Developmental studies in kindergartners and school-aged children}

Lateralization of face-selectivity Interestingly, the very same EEG frequency-tagging paradigm as used in infant studies above elicits a completely bilateral face-selective response in preschool children (Lochy et al. 2019, 2020) (Fig. 5C) and even in 8-12-year-olds (Vettori et al. 2019; Fig. 5C). Likewise, there is no significant hemispheric lateralization of the $\mathrm{N} 170$ in response to faces in children of various age groups until late adolescence (Dundas et al. 2014; Kuefner et al. 2010).

\footnotetext{
8 Technically, a response recorded over EEG electrodes positioned over the RH could potentially be generated from sources in the $\mathrm{LH}$, although this is unlikely for the focal occipito-temporal response as displayed in Figs. 4 and 5

. Due to the undetermined inverse problem in EEG (or MEG), source localization algorithms applied to such data would not enable substantial progress on this issue. However, testing an adapted frequency-tagging paradigm with functional near-infrared spectroscopy (e.g., slowing down the face stimulation frequency as in fMRI, see Gao et al. 2019), recording neural signals under the sampled area, could provide decisive evidence.
}

These EEG results are in line with strictly bilateral faceselective fMRI responses observed in 5-9-year-old children (Golarai et al. 2007; Scherf et al. 2007; Natu et al. 2016; Hildesheim et al. 2020). In older children, face-selective regions in the VOTC (and superior temporal sulcus, STS) progressively enlarge with small, if any, right lateralization effects (7-11 years old, Gathers et al. 2004; Golarai et al. 2007; Peelen et al. 2009; Natu et al. 2016) that become clear only at adolescence (Cohen Kadosh et al. 2011; Joseph et al. 2011). While these observations are usually taken as supporting a (slow, gradual) effect of literacy on RH lateralization for face recognition (Behrmann and Plaut 2015, 2020), a number of fMRI studies report RH dominance for faces already in young children (4 years old: Cantlon et al. 2011; 6 years old: Centanni et al. 2018; Dehaene-Lambertz et al. 2018: Fig. 6; Feng et al. 2021; 8-10 years old: Monzalvo et al. 2012).

In the same vein, experimental findings in children tested with divided visual field stimulation are inconsistent across studies. For instance, while relatively recent divided visual field presentation studies reported no LFV/RH advantage for face recognition in children (7-9 years old) or teenagers (Dundas et al. 2012, 2014), early studies with this technique reported RH lateralization for faces already at the earliest age tested (5 years old), without any evidence of an increase of this effect at later stages of development (Ellis 1983 for review).

Correlations between face- and word-selective neural responses The reading-LNC hypothesis predicts a positive correlation during development between LH lateralization for words and $\mathrm{RH}$ lateralization for faces, with a negative correlation between faces and words in the LH. Surprisingly, few studies have directly addressed these predictions, with mixed outcomes. Specifically, a fMRI study in 6-year-old children reported a reduction in the volume of face-selective responses in the left VOTC $(r=-0.34)$ with increased selective responses to letter strings (Centanni et al. 2018). However, since neural category-selectivity is defined in that study by directly contrasting faces and letter strings (Faces $>$ Letters and Letters $>$ Faces), this result is trivial and cannot be taken as supporting the competition hypothesis. Indeed, if responses to letters increase, the contrast Faces $>$ Letters will automatically lead to weaker responses to faces. In any case, the increase in "letter-selectivity" in the LH did not lead to a significant increase of "face-selectivity" in the RH (Centanni et al. 2018).

With EEG recordings, Li et al. (2013) reported a strong negative correlation between the word N170 left-lateralization (amplitude left-right) and the face right-lateralization (amplitude right-left) $(r=-0.51$ with $N=81)$ : the more leftlateralized word N170, the less right-lateralized face N170. While the authors interpreted this observation in favor of the 


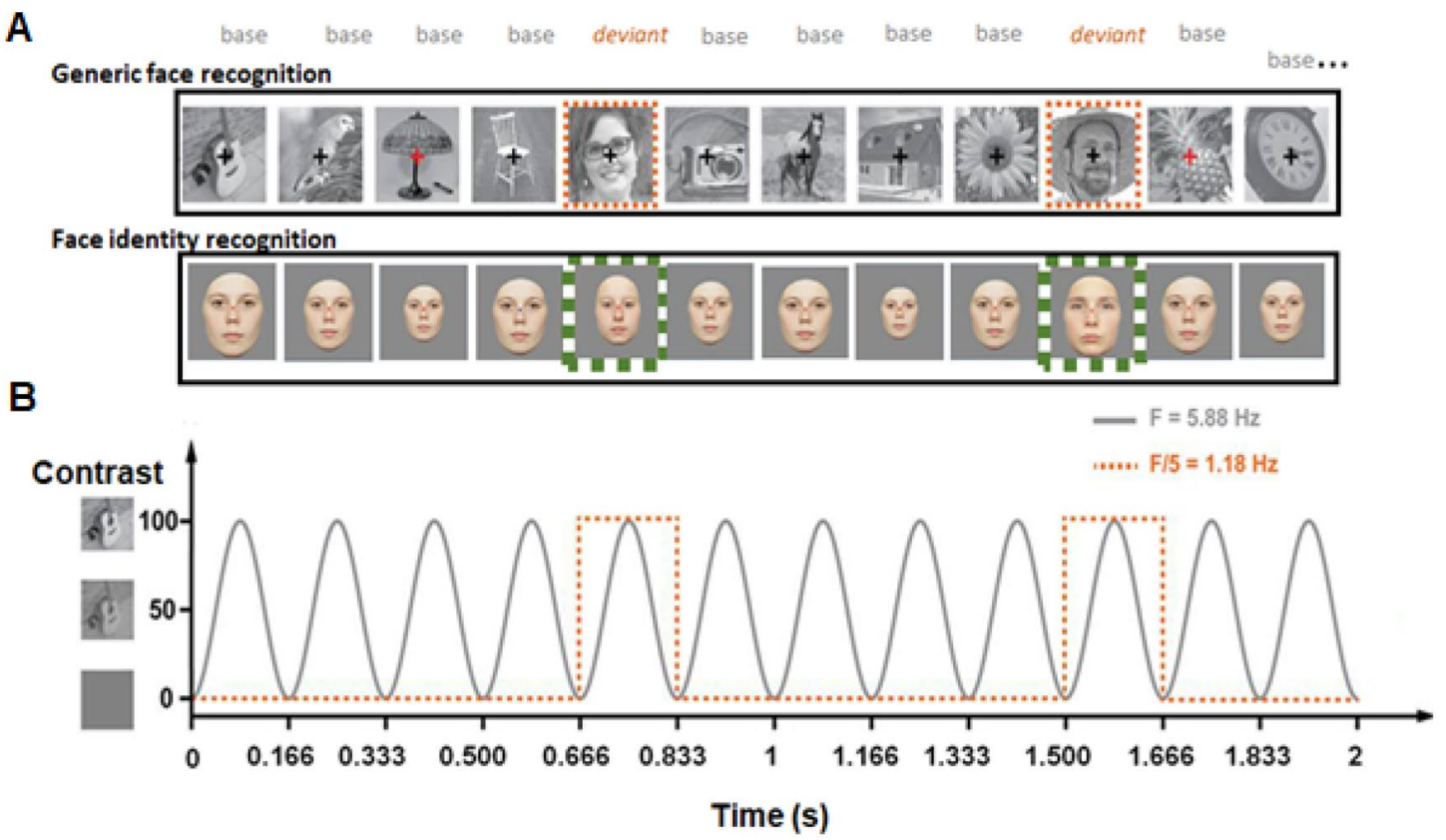

\section{AGE GROUP}

C

TASK
$\begin{aligned} & \text { Generic face } \\ & \text { recognition }\end{aligned}$
Face identity
recognition

4-6 months old

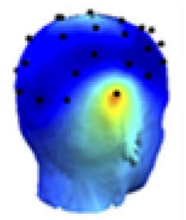

No clear
evidence

De Heering

\& Rossion,

2015
5 years old

8-12 years old

Adults
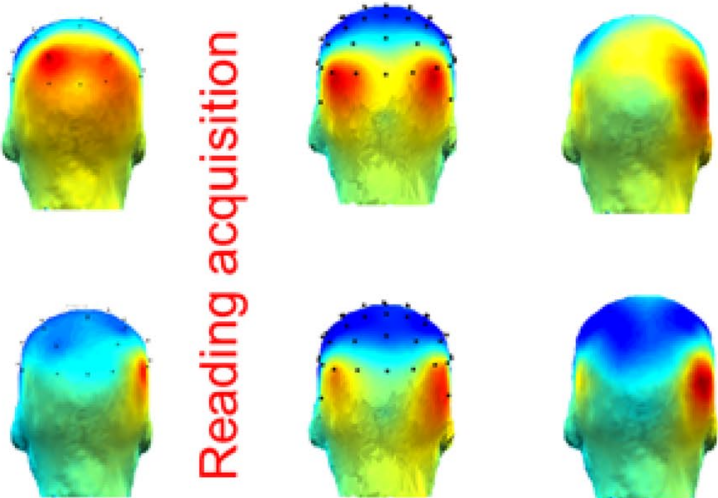

Lochy et

al., 2020

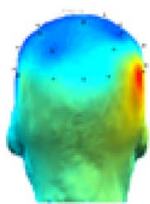

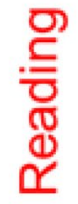

Vettori et al., 2019
Rossion et al. 2015; LiuShuang et al., 2014
Fig. 5 Frequency-tagging paradigms for face recognition and scalp topographies of responses across different age groups. A Example of visual stimulation sequences. Top row: Generic face recognition, where base stimuli are constituted of non-face objects, interspersed every 5 items with highly variable images of faces (various identities, viewpoints, ...) (from de Heering and Rossion 2015; Rossion et al. 2015). Second row: face identity recognition, where a base unfamiliar face identity is repeated throughout the sequence with random variations of size, and different identities are inserted every five stimuli. B Stimuli flicker on the screen at $6 \mathrm{~Hz}$ (6 stimuli per second) with a sinusoidal contrast modulation, with faces or different identities inserted every 5 stimuli $(1.2 \mathrm{~Hz})$. C Topographical representation of selective responses on the back of the head in different age groups across studies. Top row: generic face recognition with $\mathrm{RH}$ responses in infants (De Heering and Rossion 2015), and bilateral responses at 5 years old (Lochy et al. 2019, 2020) and 8-12 year-old children (Vettori et al. 2019). Bottom-row: face identity recognition, with no clear evidence identified in infants so far in this paradigm, but RH dominant responses found from 5 years old onwards (Lochy et al. 2020; Vettori et al. 2019; Liu-Shuang et al. 2014) 
A

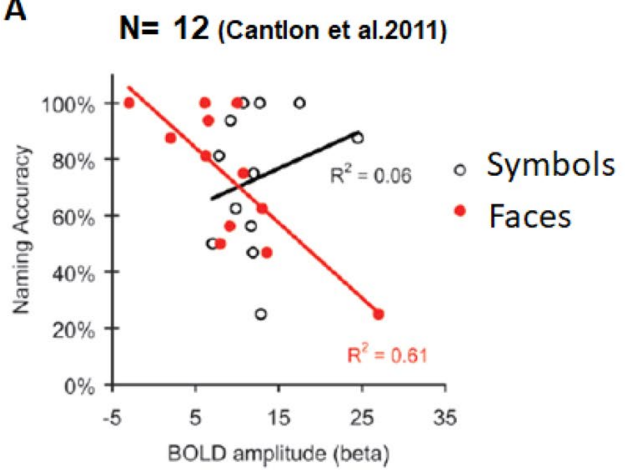

C

$\mathrm{N}=34$ (Lochy et al., 2019)

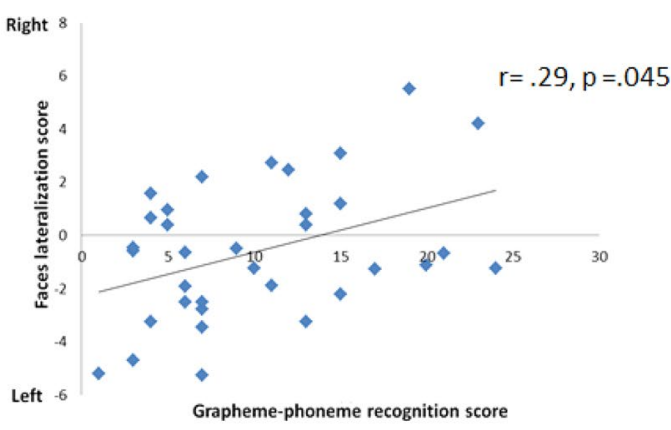

B

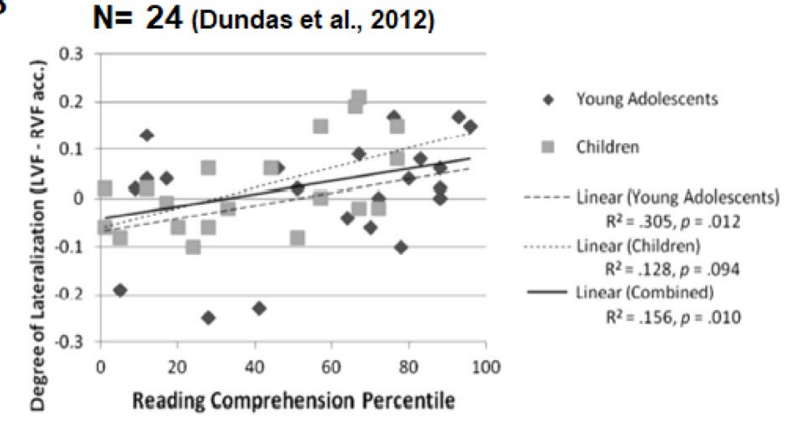

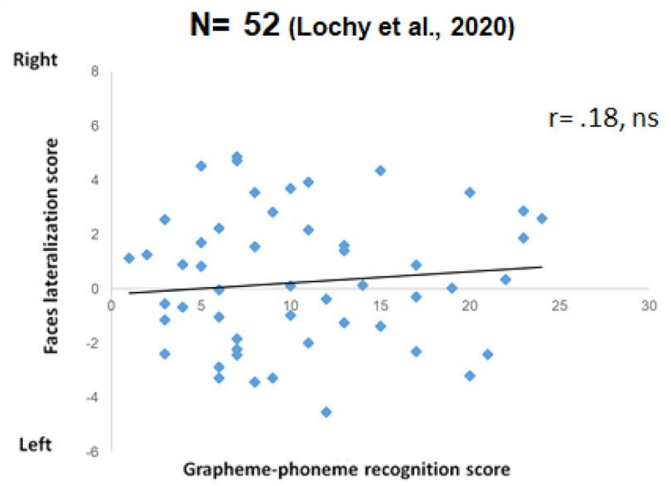

Fig. 6 Relationships between reading abilities and lateralization for faces. A The results from Cantlon et al. (2011), in 4-5-year-olds, show a negative relationship between naming accuracy (single letters and digits) and the BOLD response for faces in the LH. The correlation is based on 12 data points only, with a clear outlier on the bottom right driving the significant effect. B Dundas et al. (2012) found a small correlation in teenagers $(N=25)$ between RH lateralization

lateralized neural competition hypothesis, from our understanding, it actually goes against the view that the emergence of LH lateralization for words would increase $\mathrm{RH}$ lateralization for faces. Finally, in another fMRI study using a classifier approach, there was no relationship between the word classification in the left VOTC and the face classification in the right VOTC, or between their laterality indexes, suggesting independent development of category-selective neural responses to faces and written words in this region (Nordt et al. 2021).

\section{Correlations between reading ability and face-selective} responses Significant correlations of reading scores with lateralization to faces have been reported in a handful of studies, in apparent support of the reading-LNC hypothesis. For instance, $\mathrm{Li}$ et al. (2013) contrasted the N170 amplitude to faces in 5-6-year-old children with higher and lower reading abilities, claiming to find support for the readingLNC hypothesis (Fig. 1 of that paper). However, as reported by the authors in their text and another illustration, higher word reading abilities in 5-6 years old children correlated for faces derived from accuracy in divided visual field stimulation and reading comprehension percentile. In C, D Lochy et al. (2019, 2020) tested generic face recognition with EEG frequency-tagging in 5 -year-old children, finding a small positive correlation between reading score and lateralization score with 34 children. However, the correlation was no longer significant when adding participants to reach a sample of 52 children (2020)

negatively $(r=-0.27)$ with the right-lateralization of the N170 for faces, a result that we interpret again against the hypothesis. $^{9}$

In very young children (4-5 years old), a negative relationship between the fMRI response to faces in the left VOTC and reading abilities (naming single characters) has been found ( $r=-0.78$ in Cantlon et al. 2011; Fig. 6A), as well as a signal increase for faces near the right FFA correlating with reading speed in 6 years old (Dehaene-Lambertz et al. 2018). On the other hand, Dundas et al. (2012) reported RH lateralization scores for faces in divided visual field studies that significantly correlated with behavioral reading performance $(r=0.55)$ only in teens and not in children (Fig. 6B). Moreover, with the exception of Li et al. $2013(n=81)$, in all of these studies, several correlation coefficients are computed without correcting $\mathrm{p}$ values, and

\footnotetext{
9 To the best of our understanding, this negative correlation interpreted in support of the hypothesis cannot be due to the negative polarity of the N170 component.
} 
Fig. 7 Evolution of responses to letter strings and to faces in a longitudinal study over testing sessions (S1 to S6) (adapted from Dehaene-Lambertz et al. 2018). Illustrated here are the results of one child, from the summer before school started [2 months before ( $\mathrm{S} 1)$ and 10 days before (S2)] and during the first year of primary school (from S3 to S6, approximately every 2 months). The RH dominance for face-selective neural responses is present from the start of the study and, while impressive changes occur at the VWFA location for words, is remarkably stable across testing sessions

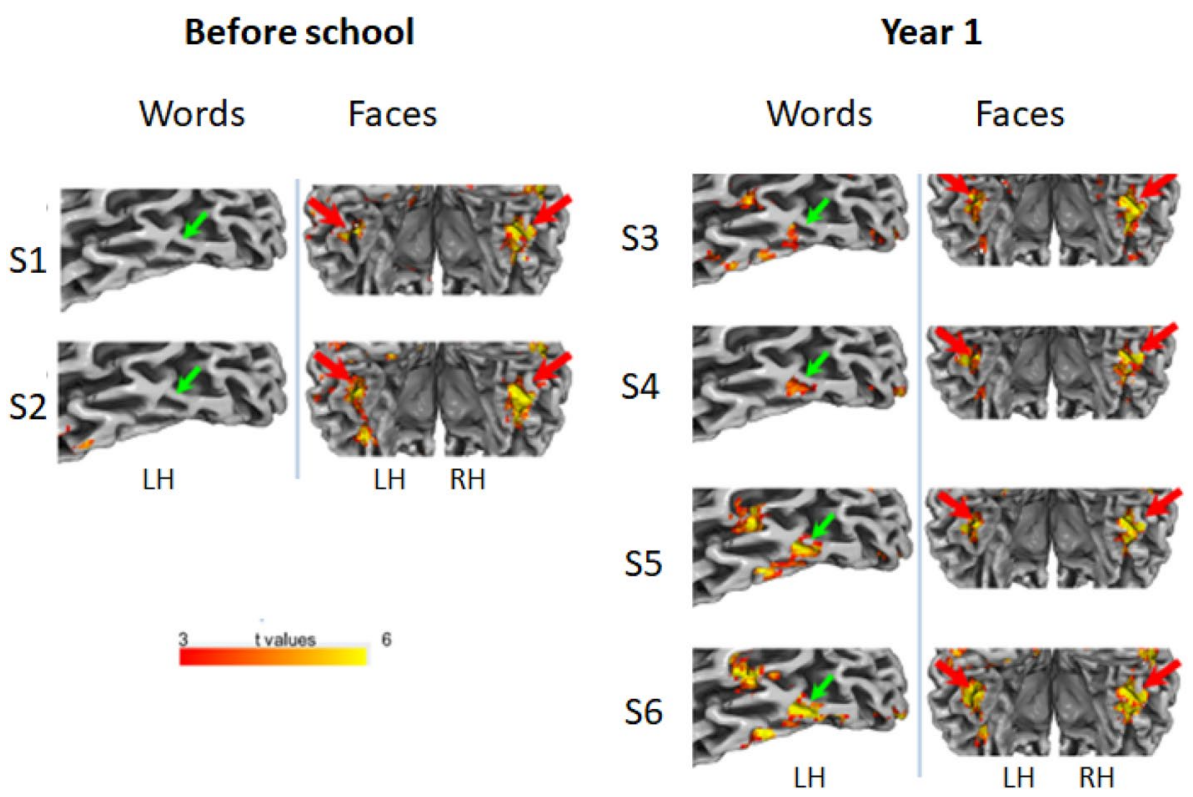

the sample sizes are small for correlation analyses $(n=12$, $n=10, n=24$, respectively). The importance of this latter factor is highlighted by the following comparison: while Lochy et al. (2019) also reported a significant correlation $(r=0.29)$ between reading performance and $\mathrm{RH}$ lateralization of a face-selective frequency-tagged responses, this effect disappeared entirely when the population of children tested increased from 34 to 52 (Lochy et al. 2020; Fig. 6C, D). Moreover, in the most recent fMRI study testing this hypothesis in a large sample $(N=60,6-9$ years old $)$ and with left VOTC activation for words positively correlating with reading level, RH activation for faces correlated with age independently of reading level (Feng et al. 2021).

Developmental dyslexia A number of developmental studies have also explored the impact of a disorder in learning to read (developmental dyslexia) on the $\mathrm{RH}$ lateralization for faces, again with mitigated evidence. Here, the rationale is that since dyslexia is associated with weaker activation and specialization of the VWFA to print (Martin et al. 2015; Richlan 2012), there should be less competition with faces in the LH. Therefore, developmental dyslexics should show a reduced $\mathrm{RH}$ lateralization for faces.

Weaker activation and volume of the right FFA in dyslexics compared to typical readers have indeed been found in some studies (Monzalvo et al. 2012), but not in others (Perrachione et al. 2016). Moreover, while the specificity of an atypical neural representation for faces in dyslexia is claimed by some authors (Gabay et al. 2017), a more general disorder of the left ventral stream, generalizing across several categories has been found (Sigurdardottir et al. 2015; Perrachione et al. 2016). Overall, the conclusions that can be drawn from studies with this population have to be taken with great caution: dyslexia is a neurodevelopmental disorder with abnormalities in brain maturation and function that are not limited to the reading network, the LH, and even less to the specialization of the VWFA for letters (see Martin et al. 2015; Richlan 2020).

Summary of children studies In our view, the studies in children reviewed above do not provide much empirical evidence for the proposed causal influence of reading acquisition and specialization of the left VOTC for print on the RH lateralization for faces in this region.

First, the brief review above shows that RH lateralization for faces may be related to reading abilities in some studies, but their results are limited by the use of particularly small samples and/or confounding effects of age. Second, RH lateralization is not significantly linked to LH lateralization for letter strings, even though there is surprisingly little direct evaluation of this prediction. In this context, the longitudinal study of Dehaene-Lambertz et al. (2018), in which 6-year-old children were tested in fMRI at 6-7 time points during their first year of schooling, is particularly interesting (Fig. 7). In that study, face-selectivity is already found in the $\mathrm{RH}$ (around the MidFusiform gyrus, i.e., FFA) 2 months before formal reading acquisition (again against the view that this $\mathrm{RH}$ lateralization emerges only due to selectivity to print in the $\mathrm{LH}$ ). Following reading acquisition, word-selective responses in the left OT regions (i.e., VWFA) emerge significantly.

Crucially, a retrospective analysis of the initial selectivity of those voxels that became selective to letter strings shows that they were not face-selective initially, as suggested earlier by Saygin et al. (2016), and in fact, 
in full agreement with a fair evaluation of the adult study of Dehaene et al. (2010). Based on these observations, Dehaene-Lambertz et al. (2018) suggest that new visual categories, such as letter strings, invade only weakly specified cortex, while leaving face-selective cortical responses unchanged (see also the most recent fMRI study of Nordt et al., 2021). Unless one can demonstrate that further expansions of category-selective responses to faces at later developmental stages are specifically blocked in the LH, increasing RH dominance of face recognition even further, such findings speak directly against even a weak version of the reading-LNC hypothesis.

Third, while RH lateralization is inconsistently reported in young child studies, it cannot be ignored. Indeed, the fact that group-level face responses are either bilateral or RH lateralized, in particular in fMRI, but never LH lateralized, points to a genuine RH lateralization that may not be systematically captured due to the various methods, stimuli, paradigms and measures (i.e., absolute responses to faces, faces $v s$. rest, faces vs. letter strings, faces $v s$. non-face objects (including letter strings or not ...) used across studies (see Sect. 4).

Here, the issue of the level of face recognition/categorization (e.g., generic face recognition $v s$. FIR), which is usually neglected in all of these studies, may be crucial. To illustrate its importance, Lochy et al. (2020) recently compared RH lateralization to face stimuli in 52 preschool children with two frequency-tagging paradigms measuring different recognition levels. While, as already mentioned, strictly bilateral responses for the discrimination between faces and nonface stimuli were found (i.e., category-selective face responses), clear right-lateralized responses were observed for (unfamiliar) FIR measures obtained in the very same sample (Fig. 5). These findings show that incorrect conclusions regarding the (absence of) right lateralization of face recognition in early development, and of its relationship to reading acquisition, could be drawn due to the use of a limited set of measures, in particular regarding the specific face recognition function sampled.

\section{Inter-individual variability in literate adults, concurrent stimulation and handedness}

Hemispheric lateralization for letter strings and faces can vary substantially among neurotypical literate human adults (Badzakova-Trajkov et al. 2010; Cai et al. 2008). This inter-individual variability allows evaluating a corollary to the lateralized neural competition hypothesis, namely that hemispheric lateralization for letter strings and faces should correlate across individuals: if competition induces a reduction of the face-selective response in the $\mathrm{LH}$, then responses to faces and words should negatively correlate in that hemisphere. Moreover, this could lead to a compensatory increase of face-selectivity in the RH, such that a positive correlation should emerge across hemispheres between selective responses to letter strings (LH) and faces (RH). Consequently, under the lateralized neural competition hypothesis, the greater the left lateralization $(\mathrm{LH}-\mathrm{RH}$, or $(\mathrm{LH}-\mathrm{RH}) /(\mathrm{LH}+\mathrm{RH}))$ for letter strings, the greater the right lateralization $(\mathrm{RH}-\mathrm{LH}$, or $(\mathrm{RH}-\mathrm{LH}) /(\mathrm{LH}+\mathrm{RH}))$ for faces across individuals. With divided visual field stimulation, Brederoo et al. (2020) indeed recently showed a significant correlation $(r=0.29)$ between RH-lateralization at a face processing task and LH-lateralization for word processing as measured in response speed. However, this issue has been most deeply explored in a number of fMRI studies that have used a variety of indices (raw signals per hemisphere, extent of responsive voxels, difference between hemispheres, normalized indices, ...) to examine the abovepredicted correlations.

Pinel et al. (2015) tested a large cohort $(N=64)$ of individuals, reporting higher reading speed of pseudowords related to a decrease of face-related activity in the left FFA. However, there was no correlation between category-selective responses in the right FFA (faces) and left VWFA (letter strings). Davies-Thompson et al. (2016, $N=26)$ found no correlation for the number of voxels in the right FFA for faces and left VWFA for letter strings, but a positive correlation for the peak MR response, which was even stronger when fusiform cortical thickness and cortical volume were considered. While this last result apparently supports the reading-LNC hypothesis, there were also positive correlations between the peak MR responses for faces in the right FFA and those in the left FFA, and for letter strings between the right and left VWFA. Thus, as the authors conclude, the positive correlations between words and faces across hemispheres merely reflect the fact that subjects with greater activation for faces also had greater activation for letter strings, a typical confound in the direct interpretation of correlation coefficients between two measures across individuals (e.g., Dundas et al. 2014). As for hemispheric lateralization indexes (computed left-wise for both categories, $(\mathrm{LH}-\mathrm{RH}) /$ $(\mathrm{LH}+\mathrm{RH}))$ between the response to faces in the FFA and for letter strings in the VWFA, the direction of the significant correlation-which fell below threshold after removal of an outlier-was against the reading-LNC hypothesis and in line with the general conclusion of the authors.

Using explicit tasks in fMRI, Gerrits et al. $(2019 ; N=27)$ found a significant negative correlation in terms of fMRI signal in a large pre-defined section of the fusiform gyrus between face recognition and language-lateralization assessed by a word production task. However, there was no significant correlation in this region between lateralization indexes for face and written word recognition. Finally, in the most recent fMRI study of Canário et al. (2020), there 
was again no significant correlation between lateralization indexes for the VWFA (letter strings) and the FFA (faces) across the 58 individuals tested, for any of three measures of fMRI signal. Overall, while the relationship between neural activity to speech in the LH and right hemispheric lateralization of the FFA is worth mentioning, the results of these fMRI studies clearly go against a major prediction of the reading-LNC hypothesis, namely that an increase in LH lateralization for letter strings in the VOTC causes an increase in $\mathrm{RH}$ lateralization for faces in the same region (and in general).

At the behavioral level, Robinson et al. (2017) used an attentional blink paradigm (with central presentation) claiming to find interfering effects between words and face processing in favor of the reading-LNC hypothesis. However, contrary to the predictions of this hypothesis, words presented at $\mathrm{T} 1$ did not produce larger short-lag deficits for face $\mathrm{T} 2$ discrimination than pictures of glasses (in 2 experiments). Moreover, words T2 discrimination was more affected by faces than by words, a result which cannot be explained under the assumption that the paradigm used in that study is adequate to measure competition between functionally similar representations.

Using an ERP paradigm initially developed to test concurrent competition between different face stimuli (Jacques and Rossion 2004) and objects of visual expertise with faces (Rossion et al. 2004, 2007), Fan et al. (2015) showed a decrease in the amplitude of the N170 evoked by lateral face stimulation when concurrently processing known characters centrally. However, this competition effect was not stronger when faces were presented in the LVF than in the RVF, contrary to the prediction of the reading-LNC hypothesis. Moreover, while the N170 is clearly left-lateralized for the Latin alphabet (Maurer et al. 2006; Rossion et al. 2003), Chinese characters bear several similarities with faces (uniqueness, configuration, processed at an individual level, shape) and they have been shown to induce bilateral responses both in fMRI (Tan et al. 2005; Fu et al. 2002; Bolger et al. 2005; Liu et al. 2008; Wu et al. 2012) and EEG/MEG (Kim et al. 2004; Zhang et al. 2011). Finally, such neural competition effects in the same paradigm can be observed (even more strongly) for familiarization of non-letter string stimuli, such as "Greebles" and pictures of cars in car experts (Rossion et al. 2004, 2007, respectively), indicating that they are not specific to letter strings.

An important aspect to take into consideration in interindividual differences studies is the handedness of participants. Indeed, among the only four reported cases of prosopagnosia with a left unilateral lesion, three of these patients were left-handed (Tzavaras et al. 1973; Eimer and McCarthy 1999; Mattson et al. 2000), ${ }^{10}$ whereas functional damage might have been also present in the right hemisphere of the only right-handed patient (Wright et al. 2006). While the lateralization of language in these cases was unknown, their left handedness makes them more likely to be right language-dominant than right-handed people (Knecht et al. 2000; although see Packheiser et al. 2020), suggesting a systematic opposite relationship between hemispheric lateralization of language (in general) and face recognition.

In line with these observations, EEG and fMRI studies have suggested that the VWFA co-lateralizes with the language-dominant hemisphere (i.e., being right-lateralized when language is lateralized to the right hemisphere, as more often the case in left-handed people, Cai et al. 2008, 2010; Van der Haegen et al. 2012). FMRI studies have reported a smaller proportion of left-handed (73\%) than right-handed (94\%) people, with a right hemispheric dominance for a simple face task across the whole brain (Badzakova-Trajkov et al. 2010). Moreover, the FFA is bilateral or even slightly left-lateralized overall in left-handed people (Willems et al. 2010; Bukowski et al. 2013; Frässle et al. 2016b; Dundas et al. 2015; Gerrits et al. 2019).

Building upon these observations, a recent fMRI study attempted to relate language dominance to written letter strings and face lateralization in left-handed people characterized by a typical LH or atypical RH language dominance (Gerrits et al. 2019). There was a positive correlation between lateralization indexes of language and word recognition (0.65) and a negative correlation between language and FIR performance $(-0.62)$ (but see Van der Haegen and Brysbaert 2018 for an absence of correlation in performance at lateralized behavioral tasks). However, against the reading-LNC hypothesis, written words and face recognition did not inversely correlate, neither in terms of the direction nor the strength of lateralization of the response recorded in fMRI (Gerrits et al. 2019). This latter observation contradicts the findings of the EEG study of Dundas et al. (2015) who reported a negative relationship $(r=-0.65)$ between the left N170 to words and the right lateralization for faces $\left.((\mathrm{RH}-\mathrm{LH}) /(\mathrm{RH}+\mathrm{LH}))^{*}-1\right)$ independently of handedness.

In summary, if anything, the most convincing sources of evidence of a relationship between hemispheric lateralization of the two domains in adults come from observations in left-handed people who, more often than those who are right-handed, show atypical hemispheric lateralization for

\footnotetext{
10 As also noted by an anonymous reviewer of this manuscript, the prosopagnosic patient reported by Barton (2008) was ambidextrous and had in fact a bilateral VOTC lesion and is therefore not considered here.
} 
both faces and letter strings. However, these data offer at best only indirect evidence of neural competition between reading acquisition in the VOTC and right hemispheric lateralization of face recognition. This is also the case for thenotable - finding of Pinel et al. (2015) in which the increase in $\mathrm{RH}$ lateralization for faces in the FFA was positively related to left lateralization for speech in the posterior STS.

Other than that, behavioral and neural measures exploiting inter-individual variability in lateralization and performance in neurotypical adults with correlation analyses offer little to no direct support for the reading-LNC hypothesis. Admittedly, both for child and adult studies, these correlation analyses are complicated by the use of highly variable dependent measures (i.e., absolute amplitude/magnitude of brain response to faces or letter strings, category-selective responses, lateralization indexes through subtraction with or without normalization, etc.) in different and differently defined brain regions, requiring clarification and systematicity for further progress on this issue (see Sect. 5 below).

\section{Does an increase in letter-selectivity decrease face recognition performance?}

As mentioned above, the reading-LNC hypothesis predicts at least a small drop of face recognition performance with literacy (Dehaene and Cohen 2007). This prediction can also be evaluated in behavioral developmental studies, and in adult studies comparing behavioral performance of literates to illiterates.

\section{Developmental studies of face recognition}

Young human infants, even newborns, show selective behavioral and neural responses to face stimuli (Goren et al. 1975; Johnson et al. 1991; de Heering and Rossion 2015). However, face identity recognition (FIR) appears very limited at an early age and develops slowly until adulthood, maybe peaking as late as 30 years of age (Germine et al. 2011). Whether this protracted development is due to the progressive maturation of face recognition processes specifically (presumably through extensive experience with faces) or could be explained by the development of more general cognitive or task-related factors, is debated.

On the one hand, McKone et al. have argued that holistic recognition of facial identities, considered as hallmark of the specificity of the function, reaches maturity early in development, i.e., by 5-7 years of age at the latest (Crookes and McKone 2009; McKone et al. 2012). This would leave little or no room for reading acquisition to negatively affect FIR. On the other hand, a number of behavioral studies have failed to find significant reduction of FIR performance with inversion of face stimuli, i.e., a face inversion effect in children (e.g., 6-8 y.o.: Carey and Diamond 1977; Hills and
Lewis 2018; Schwarzer 2000), this effect being extremely robust in adults and also considered as a hallmark of face specificity and expertise (Yin 1969; see Rossion 2008 for review). Other studies have reported a reduced effect as compared to adults (Carey 1981; de Heering et al. 2012; Sangrigoli and De Schonen 2004), with the effect increasing over childhood and adolescence (Carey and Diamond 1977; Itier and Taylor 2004; de Heering et al. 2012; Hills and Lewis 2018). Behavioral studies in participants of Korean origin who were adopted in a French-speaking European environment after up to 9 years of age have also provided evidence of a reversal of their "other-race" face effect (Sangrigoli and de Schonen 2004; see also de Heering et al. 2010), suggesting that the face recognition system retains a great deal of experience-contingent plasticity during development for FIR.

Overall, neuroimaging investigations are consistent with such a progressive specific development of face (identity) recognition, showing an increase in face-selective responses in the fusiform gyrus from 7 years of age to adulthood (Golarai et al. 2007; Scherf et al. 2007). Under this latter view, i.e., if face recognition progressively and specifically improves during development, a dip in performance in this function, or at least a slowing down of this improvement, might be observed when children start schooling, as predicted by the reading-LNC hypothesis (Kühn et al. 2021). While there is no evidence of such a performance dip, ${ }^{11} \mathrm{a}$ major difficulty to investigate this question lies in the confounding factors that may affect face recognition performance, such as the increase of general cognitive abilities with age. Most importantly, schooling usually corresponds with an increase in socialization and thus of quantitative and qualitative experience with variable face identities, these factors playing an important role in FIR performance (Balas and Saville 2017) and the magnitude of face-selective VOTC responses (Dehaene et al. 2010; see also Balas and Saville 2015).

\section{Adult studies of illiterates/literates}

To our knowledge, there is no study in adults showing detrimental effects of literacy on face recognition performance. On the contrary, several studies show that illiterate adults perform worse than literate adults in recognizing, detecting, and naming visual objects, although these effects are not specific to any category (Huettig and Mishra 2014). In face recognition tasks of various difficulty, literates also perform

\footnotetext{
11 Early developmental studies of face recognition have instead argued in favor of a dip of performance at a later age, at around 11 years old (Carey 1992), but this has not been supported by subsequent studies.
} 
better than illiterates (Orihuela et al. 2013). Thus, rather than competing with shared visual processes for faces, literacy appears to boost face recognition, by fine-tuning object recognition mechanisms (Hervais-Adelman et al. 2019; van Paridon et al. 2020), and improving the detection, segmentation and interpretation of visual information (Huettig et al. 2018; Kolinsky et al. 2011). For instance, a positive association between literacy scores and face/object recognition was found in memory tasks (97 participants, from illiterate to highly literate) (Van Paridon et al. 2020) suggesting that older abilities are enhanced rather than impaired by the acquisition of new related abilities.

Let us note, however, the inherent difficulty in behavioral studies comparing literates to illiterates. Most often, these two groups of participants, even when they are well-matched in terms of rural/urban environment or socio-economic backgrounds, differ in other cognitive measures related to schooling, testing habits, etc. For instance, in the abovementioned study, participants with high-reading scores also displayed more general perceptual reasoning abilities, as well as higher digit-span, complicating the interpretation of the results (Van Paridon et al. 2020). The observation of a mere quantitative improvement in performance for face (identity) recognition in literates compared to illiterates could thus also rely on general cognitive abilities, better exemplar discrimination across domains (Pegado et al. 2014a, b), or familiarity with testing conditions, than literacy per se.

\section{Is face recognition qualitatively modified by letter string sensitivity?}

Assessing whether face recognition changes qualitatively with letter string sensitivity is complicated by the lack of scientific agreement about the nature of face representations (e.g., holistic $v s$. feature-based; shape or surface-based) and the most adequate paradigms to measure holistic face recognition (Rossion 2013). Perhaps for this reason, so far, the qualitative hypothesis has been tested only in a handful of studies comparing literate and illiterate adults.

At a general level, literacy is thought to change basic visual principles, such as mirror-invariance (Kolinsky and Fernandes 2014; Pegado et al. 2014a, b; Pegado et al. 2014a, b; Fernandes et al. 2016, 2021), and to enhance qualitatively analytic, partbased processing, therefore improving performance in visual search tasks (Malik-Moraleda et al. 2018). In line with this prediction, Ventura et al. (2013) claimed that literacy induces a reduction of holistic processing of faces in a composite face task (albeit with a Stroop-based version of the paradigm; see Rossion 2013). However, this hypothesis is at odd with the assumption that if face recognition is shifted towards the $\mathrm{RH}$ with literacy, then greater holistic processing should be found, not the reverse. Moreover, Cao et al. (2019) showed greater sensitivity to face orientation in literates, as well as better performance in detecting differences due to spatial configuration not only for faces, but also for houses, thus suggesting a general improvement with literacy at detecting spatial relations between components. More generally, the above-cited fMRI study of Hervais-Adelman et al. (2019) showed a representational similarity increase between text and faces in the VWFA in trained illiterates as compared to literates, in favor of the view that tuning to orthographic stimuli does not involve a loss of responsiveness to faces but may in fact induce an increase in shared aspects of the representation between text and faces.

\section{Summary}

To summarize, the reviewed scientific literature in development, in illiterate adults, or assessing inter-individual differences, does not offer much empirical support in favor of a causal influence of VOTC specialization for reading in the $\mathrm{LH}$ on the $\mathrm{RH}$ lateralization of face recognition (i.e., the reading-LNC hypothesis as referred here). The strongest arguments advanced in the literature lie in some positive correlations between reading abilities and RH lateralized face-selective responses, but the results are inconsistent and often suffer from (very) small sample sizes. Also, there is no evidence to date of a negative impact of literacy on performance for face recognition, acknowledging that the evaluation of this hypothesis is complicated by confounding factors of general cognitive abilities increase (due either to age or to schooling). Finally, the few studies that have examined left-handed participants or inter-individual variability, relating language dominance and face lateralization, offer some support to the idea that $\mathrm{LH}$ language lateralization in general-rather than letterstrings selectivity in the VOTC specifically - could contribute to RH face lateralization (Pinel et al. 2015; Gerrits et al. 2019). This possibility is discussed further in the last section of the review.

\section{Alternatives and perspectives}

If the reading-LNC hypothesis is incorrect, i.e., if RH lateralization of face recognition, which appears to be specific to the human species, is not due to neural competition with the representation of letter strings in the VOTC of the LH when learning to read, what are the alternative views? Although a full survey of these alternative accounts is beyond the scope of the present review, they are briefly discussed below. 


\section{What is right?}

\section{Global/local and holistic/analytic dichotomies}

Ever since the LH has been considered as the (main) seat of verbal function, a number of dichotomies in terms of processing modes have been proposed to contrast it to the $\mathrm{RH}$, invading the popular culture: the LH is seen as the logical, analytical, serial, rational, digital mind, while the RH as the spatial, analogic, holistic, synthetic, parallel, intuitive and artistic mind (e.g., Bogen 1969; Springer and Deutsch 1981; Bradshaw and Nettleton 1981). Beyond these caricatural dichotomies, the hypothesis that the RH is well predisposed for the processing of global aspects of the visual world, whereas the LH is well suited for processing its local aspects has been more thoroughly explored with visual stimuli.

Evidence collected in brain-damaged patients with unilateral RH or LH lesions tested with hierarchical 'Navon' stimuli (i.e., large letters made of congruent or incongruent small letters; Navon 1977) provides some support for this view (Delis et al. 1986; Robertson et al. 1988; Lamb et al. 1989; see Hellige 1993 for review) although the results of studies in neurologically intact individuals tested with divided visual field stimulation, as often, are more equivocal (e.g., Sergent 1982a, b; Boles 1984; Van Kleeck 1989; although see Brederoo et al. 2020). Most importantly, the tasks performed in these experiments often concern visuospatial attention rather than visual recognition processes per se. Indeed, rather than key regions of the ventral occipitotemporal cortex involved in object recognition, the lesions of the patients leading to such hemispheric asymmetries in global vs. local processing concern the posterior superior temporal gyrus (Lamb et al. 1990; see also Busigny and Rossion 2011 for intact processing of hierarchical Navon letters in a well-defined case of prosopagnosia). In short, a hemispheric dichotomy in terms of global vs. local visual processes may be partly valid, but does not appear to provide direct evidence to account for the RH lateralization of human face recognition, at least regarding ventral occipitotemporal brain structures.

It is this global/local dichotomy that probably inspired a subsequently proposed hemispheric dissociation, based on neuropsychological studies, between stimuli that can or cannot be decomposed in parts during visual recognition (Levine and Calvanio 1989; Farah 1991). According to this proposal, all visual forms are recognized by a combination of part-based and holistic processes across the two hemispheres: while the part-by-part analysis would be preferentially accomplished by the LH VOTC, corresponding regions of the RH would process visual objects holistically/configurally. ${ }^{12}$ On the one hand, written words provide the clearest example of objects that are decomposed into simpler unit parts (i.e., letters). On the other hand, there is overwhelming evidence that a face is processed holistically, i.e., as a single unit rather than a collection of independent parts (one eye, a mouth, etc.) (Sergent 1984; Young et al. 1987; Tanaka and Farah 1993; see Rossion 2013 for review). Therefore, according to this view, faces would be primarily recognized through holistic processes in the $\mathrm{RH}$, while written words would be mainly handled in the LH (Farah 1991).

Importantly, and although there is considerable confusion at this level in human face recognition research, this holistic/analytic dichotomy is fundamentally different than the global/local dichotomy discussed above. That is, "holistic processing" does not imply that individual parts (or features) of the visual stimulus are not important, or that the whole stimulus needs to be physically present: it is a processing mode through which the individual parts of the stimulus are not represented independently from one another, i.e., there is no part-decomposition (Farah et al. 1998; Rossion 2013). This does not mean that the parts of a face (e.g., one eye, a mouth, etc.) are not important for face recognition (as often misinterpreted), but that there is no category-selective representation of independent parts (i.e., there is no neural functional unit, e.g., a cortical minicolumn, responding only and specifically to one eye, a mouth, etc.) (see Rossion 2009, 2013 for extensive discussion of this issue).

While the study of visual (object) agnosia in neurological patients provided the impetus for this proposed hemispheric dissociation in terms of holistic/RH vs. analytic/LH recognition processes (Levine and Calvanio 1989; Farah 1991), studies with the divided visual field approach in neurologically intact participants do not provide strong support for it, with the advantages found for the RH or the LH usually depending more on the type of visual categories and tasks performed than on holistic vs. analytic modes of processing (Sergent 1983; although see Hillger and Koenig 1991).

Moreover, Farah (1991)'s influential proposal of a hemispheric dissociation between on the one hand $\mathrm{RH} /$ holistic representation/faces and LH/analytic representation/words coincided with the advent of functional neuroimaging, high-density EEG and other techniques in cognitive neuroscience, which have allowed its deeper evaluation. Over three decades of research since this initial proposal, it is fair to say that it has received only limited support. While the RH is often dominant over the LH in terms of holistic

\footnotetext{
12 The terms 'holistic' and 'configural' are sometimes used to refer to different concepts in human face recognition research, but they are used as synonyms here (as proposed and discussed extensively in Rossion 2009, 2013).
} 
processing of faces (e.g., divided visual field studies: Parkin and Williamson 1987; Hillger and Koenig 1991; neuroimaging: Rossion et al. 2000; Schiltz and Rossion 2006; Harris and Aguirre 2010: EEG: Jacques and Rossion 2009), this difference seems to be more quantitative (i.e., a reduced face-selective activity in the RH coinciding with a reduced holistic representation) than qualitative (see also Meng et al. 2012; for review: Yovel 2016). Specifically, there is no evidence that face-selective neural populations in the $\mathrm{LH}$ represent the parts of a face independently.

Most importantly, going beyond lesion studies, functional neuroimaging and EEG studies point to a fundamental contradiction between the holistic/analytic view of hemispheric lateralization and the respective representation of faces and words across the two hemispheres that was not apparent in lesion studies. That is, while representation of faces in the VOTC is bilateral with a RH dominance, representation of letter strings is much more lateralized (to the left hemisphere) in this region. In particular, the so-called FFA is typically identified in both hemispheres while the VWFA is strongly left-lateralized in readers of alphabetic writing systems, and is sometimes identified only in the LH (e.g., Cohen et al. 2000; McCandliss et al. 2003; Davies-Thompson et al. 2016; Canario et al. 2019; Kubota et al. 2019; Fig. 2). Likewise, the N170 ERP component is often only slightly right-lateralized for faces, but much more left-lateralized for printed letter strings (e.g., Rossion et al. 2003; Fig. 1E).

Following the holistic/analytic account of hemispheric lateralization for faces, this would imply that these latter stimuli are processed both holistically and analytically (with an advantage for holistic processes), while letter strings would be processed essentially analytically. Yet, if anything, the opposite is true: while, as mentioned above, faces may be represented only holistically/configurally, both part-based and holistic representations are important for written words. That is, in alphabetic systems, recognition needs to operate both at the single letter level, each letter being associated with a specific sound during most formal acquisition procedures (which may enhance an analysis of component features of the stimulus, Perfetti 1992; Yoncheva et al. 2010, 2015) and at the level of the whole stimulus (as evidenced by phenomena such as the word superiority effect, Reicher 1969; see also e.g., Martelli et al. 2005; Wong et al. 2019). Hence, following this logic, selective representations of faces should be almost only limited to the RH while those of familiar orthographic letter strings should be bilateral: the exact opposite to what is observed. In summary, the holistic/ analytic dichotomy does not appear to provide a satisfying explanatory account of the right hemispheric lateralization of face recognition.

\section{From spatial frequencies to resistance to degradation}

According to another influential hypothesis originating in the 1980s, face recognition would be lateralized to the $\mathrm{RH}$ because it would depend essentially on coarse variations of luminance across the stimulus, i.e., low spatial frequencies (LSF). In contrast, the recognition of letter strings would essentially rest on the processing of edges, i.e., high spatial frequencies (HSF). The connection between SF and hemispheric asymmetries in high-level processing was put forward by the late Justine Sergent (1982a, b), who reported a number of theoretical and empirical and contributions to this hypothesis, testing it with face stimuli in particular (e.g., Sergent 1983, 1985, 1987; Sergent and Hellige 1986). According to Sergent's hypothesis (see also Ivry and Robertson 1998) applied to vision, whereas early processes unfold symmetrically in the two hemispheres, the RH preferentially operates on the low-frequency outputs of the visual channels, and the LH is more adept at operating on higher spatial frequencies. The fact that low frequencies are more resistant to degradation, and more easily resolvable at low contrast, far away or during motion, may give the $\mathrm{RH}$ a critical role in face recognition when the prevailing conditions prevent the resolution of HSF. The contribution of the LH would increase when fine visual operations are required (perhaps driven by reading acquisition, Ossowski and Behrmann 2015), but this hemisphere would also be more vulnerable to reduction in the redundancy of incoming information (Sergent 1985). This hemispheric balance across SF bands is also considered to account for the early infant bias towards the LVF for their mother's face, thought to be the result of the faster maturation rate of the $\mathrm{RH}$ at a time at which the infants' visual system mainly extracts LSF from facial inputs (de Schonen and Mathivet 1989).

However, as for the holistic/analytic hemispheric dichotomy described above, the hypothesis of a differential sensitivity to SF to account for the RH dominance in face recognition has received little empirical support. In divided visual field stimulation studies, differences between visual recognition of complex stimuli in the LVF and RVF are also more susceptible to the effect of task and stimulus category than to SF per se (Sergent 1985; Sergent 1987; see Hellige 1993). While other techniques in cognitive neuroscience generally support Sergent (1986)'s view of a coarse-to-fine accumulation of evidence for face recognition, they do not appear to support RH/LH imbalance in processing LSF/HSF, respectively (Goffaux et al. 2011; Quek et al. 2018). In fact, the RH merely appears to be more sensitive or more resistant to degradation of visual inputs than to LSF per se, again pointing to a quantitative rather than a qualitative difference between hemispheres at this level (Peterzell 1991, 1997).

Finally, also in common with the holistic/analytic dichotomy, there is a fundamental contradiction between the 
relative use of facial cues available at different frequency ranges for visual recognition and the $\mathrm{RH}$ lateralization for faces. With respect to faces, LSF essentially convey information about the general shape, outer contour, and hairline of a face while HSF carry information concerning inner features, such as texture elements and the specific shape of the eyes, nose, and mouth (Sergent 1986; Morrison and Schyns 2001). Accordingly, recognizing a stimulus as a face can be achieved based on very coarse cues (Sergent 1986; e.g., as low as 4.22 cycles per image for face-selective responses, see Quek et al. 2018) while the recognition of its identity (FIR) depends on cues available at higher SF ranges (Sergent 1986; Morrisson and Schyns 2001; Näsänen 1999; Yan et al. 2020). Yet, compared to generic face recognition, it is FIR (even when based only on internal features) that is associated with an enhanced RH lateralization (Lochy et al. 2020; Jacques et al. 2020; Fig. 5).

\section{What is left ? Conceptual and methodological considerations for a revised lateralized neural competition account}

The brief survey above suggests that there is no strong alternative in the scientific literature to the view that the RH lateralization for faces in the human brain is directly or indirectly caused by neural competition with letter string sensitivity in the left VOTC. The lack of solid alternative may partly explain why this read-LNC hypothesis is currently influential and very actively tested. Yet, in the present review, we have provided an extensive critical analysis of this hypothesis, demonstrating that it is not well supported. An intriguing possibility emerging from this analysis is that the long-standing view of RH lateralization for faces being due to cortical competition with LH lateralized functions, language in particular (Ellis 1983; Corballis 1983, 1991), is correct, but that this competition is not initiated and operated at the level of the VOTC. Instead, the (early) specialization for phonological and semantic aspects of language in the occipito-parieto-temporal junction and perisylvian area (Dehaene-Lambertz et al. 2002; Rosselli et al. 2014 for review) may be the driving factor for an initial RH lateralization of face-selective regions in the middle and posterior sections of the human STS. In turn, due to spatial proximity and efficiency of connectivity, VOTC regions would become preferentially selective for faces in the RH as compared to the LH. Such a revised account of the hypothesis would agree with the fact that the right hemisphere is less lateralized in general (Corballis 1991; Gotts et al. 2013), with observations made in left-handed individuals (Sect. 3, e.g., Gerrits et al. 2019) as well as significant correlations between left pSTS/mSTS responses to speech and right FFA activity for faces (Pinel et al. 2015). It would also be in line with the strong, human-specific, $\mathrm{RH}$ lateralization at the level of these regions of the pSTS/mSTS (Fig. 1A, B), and with the relative developmental immaturity of the main function of the VOTC cortical face network, i.e., face identity recognition, compared to face recognition functions carried out at the level of the STS (i.e., recognition of dynamic aspects of faces, such as head orientation, gaze direction or to a lesser extent facial expression; Haxby et al. 2000; Duchaine and Yovel 2015). Beyond the need to include (the development of) this 'dorsal' cortical face network (or the 'third pathway' specialized in social perception, see Pitcher and Ungerleider 2021) and the functions that it subtends, we conclude this review below by proposing a number of conceptual clarifications and methodological improvements for a proper evaluation of any language-related lateralized neural competition hypothesis in future research.

\section{Acknowledging and clarifying functional differences between faces and words}

Similarities between the processing of written words and faces (e.g., holistic processing, foveal bias ...) are often emphasized by proponents of the reading-LNC hypothesis. While this is interesting, we think that it is important to acknowledge at the outset the clear differences between these types of stimuli and the nature of the respective recognition functions that they are associated with. Faces are 3D dynamic stimuli, predominately curved, and made of parts that do not stand alone. In contrast, written words are 2D shapes, containing edges and junctions, and letters may recombine for other meanings. Face recognition is acquired incidentally and improves from birth to adulthood, while learning to read requires an effortful, explicit learning process starting usually only after a few years of development. While faces convey a great deal of social cues leading to many types of recognition functions (e.g., identity, expression, gender, head orientation, etc.) and may be associated with names and both verbal and nonverbal semantic information, words are strongly linked to phonology, to language production, and more generally to semantics.

In the time-scale of the evolution of the species, word recognition is a recently acquired skill (5000 years) and until a few hundred years ago, only a small proportion of the population could read. In fairness, human face recognition has also certainly experienced significant changes in most human populations over the last 5000 years (i.e., since the emergence of early civilizations and populations of thousands of individuals living in a city, changing forever the status of an unfamiliar face). Yet, it is arguably an older evolutionary skill which, unlike word recognition, is shared partly by other animal species (although with important differences even compared to non-human primates, e.g., in terms of face identity recognition; see Rossion and Taubert 2019). 
Reading is built on the pre-existence of speech, as it puts in relation speech segments (phonemes, syllables or words, depending on the system) to arbitrary written symbols, that involve a strong serial processing component in alphabetic languages. According to most reading acquisition methods, words are initially processed with an analytic visual strategy, and the issue of whether orthographic learning (of frequent words) allows them to be processed entirely holistically is an open question. In contrast, while parts/features of faces are the building blocks of recognition, part-based processes are largely inefficient in face recognition, as evidenced in neurological patients with prosopagnosia who are left to rely on this processing mode (Farah 1990; Van Belle et al. 2010). Acknowledging and characterizing in depth these fundamental differences from the outset is key to define the conditions under which faces and visual words/letter strings could truly overlap and/or compete for cortical representations and processes in the human brain.

\section{Relying on independent, controlled, measures of category-selectivity}

A major issue for the reading-LNC hypothesis is that studies do not, or rarely adequately, isolate category-selectivity, which is at the core of the (visual) recognition process, according to the definition adopted at the beginning of the present review. Instead, "raw" or "absolute" neural responses to faces (e.g., N170 amplitude to faces, Dundas et al. 2014), or responses to faces compared to basic visual stimuli that are not matched for low-level visual cues (e.g., Fig. 4) are sometimes measured. Moreover, in several studies, the approach used to define regions of selectivity to faces or words is problematic. For instance, the FFA is sometimes defined by the contrast faces-letter strings (Centanni et al. 2018). In these conditions, responses to letter strings and faces are not defined independently of each other (even if an independent functional localizer is used), and any increase in the response to letter strings in the LH will lead to a decrease in the "selective" response to faces, erroneously interpreted in favor of the reading-LNC hypothesis. This methodological confound also plagues a number of fMRI studies that include letter strings among other stimuli in their definition of face-selective response (i.e., faces vs. other categories; e.g., Dehaene-Lambertz et al. 2018). In our opinion, it is necessary to define face-selectivity completely independently of responses to letter strings, to measure its degree of hemispheric lateralization and size, and then test whether letter-selectivity affects this lateralization.

As for the definition of letter-selective brain regions, the same methodological issue stands (e.g., the definition of the VWFA by contrasting letter strings to faces in Centanni et al. 2018). Moreover, depending on the contrasted material (checkerboards, pseudofonts, or symbols), the location of the area with greater selectivity for letter strings can vary substantially (e.g., Fig. 2) from the "classical" VWFA with posterior coordinates (Talairach atlas: $y=-54$; Cohen et al. $2000)$ to more anterior VOTC regions $(y=-42$; Olulade et al. 2013; Turkeltaub et al. 2003; see also Martin et al. 2015). Further, depending on the tasks and contrasts used, this region is sometimes considered as being exclusively prelexical (Vinckier et al. 2007; Vogel et al. 2012) or lexical (Glezer et al. 2009, 2015), while its true selectivity to letter strings over object shapes can even be debated (see Fig. 3 above, from Dehaene et al. 2010, in which the "VWFA" response to pictures of tools is larger than to letter strings in all groups tested; see also Price and Devlin 2003; Starrfelt and Gerlach 2007). Future studies addressing a lateralized neural competition hypothesis should clarify these issues and develop more standard protocols, preferably with implicit tasks, in terms of the visual stimuli that are used to define selectivity, both for faces and letter strings.

\section{Defining the face recognition functions and levels that are evaluated}

Another important issue is that different techniques evaluating the LNC hypothesis measure different face recognition functions. Usually, behavioral measures during divided visual field stimulation evaluate face identity recognition (FIR), whereas neural measures (at best) reflect generic face recognition, i.e., category-selective responses to faces. Thus, the type and level of facial recognition functions assessed are different across different methodologies. This is unfortunate because, in line with the early and consistent neuropsychological observations that RH lesions are dominant in causing a deficit in identity recognition, not the ability to recognize faces as faces (e.g., Rossion et al. 2011), this factor is key in evaluating RH lateralization for faces, as shown perhaps most clearly in the children study of Lochy et al. 2020. In that study, as already mentioned, strictly bilateral responses for the discrimination between faces and non-face stimuli were found (category-selective face responses), but clear right-lateralized responses were observed for identity recognition (of unfamiliar faces) in the exact same sample of children (Fig. 5). This is also the case in human intracerebral recordings, where the $\mathrm{RH}$ advantage in the VOTC is substantially larger when measuring (unfamiliar) face identity recognition (Jacques et al. 2020) than the recognition of faces among other objects (Jonas et al. 2016; Hagen et al. 2020).

Note that while such observations point to a qualitative difference between hemispheres (i.e., an interaction with the face recognition level), they could also be accounted for by a quantitative difference: if the RH contains larger populations of neurons involved in face recognition, then the difference between hemispheres is particularly salient when testing for 
the most difficult recognition level, i.e., FIR. This quantitative difference between hemispheres in terms of neural face representation could also explain why VOTC lesions, or electrical intracerebral stimulation in these regions, cause FIR impairments more often when they occur in the $\mathrm{RH}$ than in the LH (Bouvier and Engel 2006; Jonas and Rossion 2021). In short, before drawing conclusions about the hemispheric lateralization of the face recognition function in a given individual or at the population level, we recommend to explore it at least both at the level of category-selectivity and of individual recognition of face exemplars.

\section{Using implicit neural measures of the face recognition}

The study of hemispheric lateralization of visual recognition has traditionally been based on behavioral measures collected in neuropsychological patients (including splitbrain patients, e.g., Gazzaniga and Ledoux 1978) or neurologically intact individuals tested with divided visual field stimulation (see Bradshaw and Nettleton 1981). In contrast, studies performed in the past three decades have provided a flurry of direct and indirect neural measures in/over the two hemispheres, which have often been difficult to reconcile with these behavioral measures. On the one hand, the permanent or transient impairment of a specific behavioral ability such as FIR (i.e., in prosopagnosia) can be spectacular and represent an invaluable source of information to understand the critical contribution of a hemisphere or a specific brain region (Jonas and Rossion 2021). On the other hand, explicit behavioral measures of face recognition collected in neurotypical individuals during divided visual field stimulation are often difficult to interpret because they reflect a mixture of numerous sensory, cognitive and motor processes.

For this reason, comparing literates and illiterates in explicit behavioral tasks (of face recognition) is confounded by many factors that have nothing to do with the visual recognition process per se (e.g., understanding of task instructions), often leading to superior performances in literate populations (e.g., Hervais-Adelman et al. 2019). Moreover, behavioral responses during divided visual field stimulation can reflect the outcome of many higher-level processes that are not necessarily lateralized, or lateralized according to the stimulation side, making the interpretation of such studies often difficult (see Sergent 1982a, b). Neural measures are therefore invaluable to evaluate a lateralized neural competition hypothesis, not only because they provide more information in terms of spatial and temporal localization of the processes of interest, but also because they can be collected in the absence of an explicit task. In particular, since frequency-tagging (or fast periodic visual stimulation) studies provide valid, objective, sensitive, and reliable quantifiable measures of face recognition in a frequency-domain EEG representation, usually in a few minutes of testing (see the recent review Rossion et al. 2020), they may have a major role to play in future studies evaluating any revised lateralized neural competition hypothesis. In addition, this approach also generates sensitive left-lateralized measures of letter strings recognition in adults and children (Lochy et al. 2015, 2016, 2018), providing an invaluable tool to implicitly measure and compare the evolution of lateralization of function for both face and letter string processing during development (Fig. 5), and between illiterate and literate individuals in future studies.

\section{Acknowledging the distributed cortical network for face (and word) recognition}

Neuroimaging studies investigating the reading-LNC hypothesis often focus exclusively on face-selective responses in the lateral middle section of the fusiform gyrus, i.e., the FFA. While this region typically presents with the largest face-selective activity in fMRI (e.g., Kanwisher et al. 1997; Gao et al. 2018) and intracerebral EEG (Jonas et al. 2016; Hagen et al. 2020) and appears to be critical for FIR (as also shown by recent lesion overlap analyses of cases of prosopagnosia; Cohen et al. 2019), there are many clusters of voxels with significantly higher neural activation to pictures of faces than non-face visual stimuli in the VOTC, up to the temporal pole (as well as in the Superior Temporal Sulcus (STS) (e.g., Rossion et al. 2012; Zhen et al. 2015; Gao et al. 2018; for reviews see Duchaine and Yovel 2015; Grill-Spector et al. 2017; Fig. 1D, F). These face-selective cortical clusters are usually considered as discrete components, i.e., processing stages, of a well-defined neuro-functional network in the human brain, with a definite pattern of anatomo-functional connectivity (Pyles et al. 2013; Elbich et al. 2019). They tend to all show RH lateralization and, contrary to the FFA, remain lateralized at the group level to the RH in left-handed individuals (Bukowski et al. 2013).

Although apparently less distributed, letter string representations have also been identified in several subregions in a postero-anterior axis (Vinckier et al. 2007; Grill-Spector and Weiner 2014), with selective responses to letters independently of their organization rather localized in the inferior occipital gyrus, and higher-level selective responses to words/pseudowords in more anterior ventro-temporal regions of the mid-fusiform gyrus (Thesen et al. 2012; Lochy et al. 2018). A proper evaluation of any revised language-related lateralized neural competition hypothesis needs to consider not only the region of the lateral Mid-Fusiform gyrus, but at least the whole network of (VOTC) face-selective and word-selective regions. 


\section{Defining representation overlap and competition at the neuronal level}

Finally, for significant progress in evaluating a languagerelated lateralized neural competition hypothesis, substantial revision of this hypothesis at the conceptual level may be required.

A key issue is whether neural competition implies overlap of representation or not, i.e., whether a neural population in the VOTC may truly respond selectively to both faces and letter strings (i.e., vs. their respective control stimuli). While neural competition is typically conceptualized as the driving factor for a neat separation of VOTC representation for different categories, such as faces and letter strings, an apparent partial overlap in representation (e.g., between the FFA and VWFA Fig. 2; see Davies-Thompson et al. 2016) even in the adult brain is in fact also considered in support of the reading-LNC hypothesis (Nestor et al. 2013; Robinson et al. 2017; Behrmann and Plaut 2020). Thus, without clarification at this level, the reading-LNC hypothesis appears unfalsifiable.

In this context, a recent human intracerebral study with a large sample identified a moderate degree of overlap in the VOTC between category-selective responses to faces and words (i.e., 30\% of recorded electrode contacts). Moreover, there was no (positive or negative) correlation of face-selective and word-selective amplitude at these overlapping locations, suggesting that these overlapping contacts recorded spatially distinct populations of neurons for the two visual categories (Hagen et al. 2021). A clear theoretical framework of a language-related lateralized neural competition hypothesis in terms of overlap of representation is necessary to avoid that such findings are taken by some in support of the neural competition hypothesis and by others against it.

Directly related to this issue, the reading-LNC hypothesis evaluated here has been often defined as reflecting a form of "neuronal recycling" (Dehaene and Cohen 2007), a terminology adopted by a number of authors but avoided deliberately in the present review since it is misleading at many levels. For a start, the term "recycling" usually refers to the process by which used (waste) material is converted into (usually) new material, not the novel use/ repurposing of this material per se. An analogy at the neural level would imply that the neural representations are somehow transformed, and do not simply become tuned to a different type of sensory inputs. Moreover, recycling would seem to imply the re-use of neural representations that have been already (completely) used for another function. However, face (identity) recognition undergoes a long developmental process until adulthood (Hills and Lewis 2018), characterized by a progressive increase in VOTC representation (Golarai et al. 2007; Scherf et al. 2007; Natu et al. 2016). Therefore, if letter string selectivity invades cortical regions that are not yet selective to faces (or any category) during development (Dehaene-Lambertz et al. 2018), or only weakly selective, the term "recycling" is also incorrect at this level and should not be revised (or recycled indeed) once again, but abandoned.

Also against the notion of "neuronal recycling", there is no evidence that regions that end up responding selectively to letter strings in the left VOTC of literate adults were predetermined genetically (i.e., selected in evolution) to respond selectively to faces. Indeed, despite gross anatomical constraints driving, e.g., the localization of these regions to the lateral rather than the medial fusiform gyrus (Grill-Spector et al. 2017), there is a large amount of variability in the location of face-selective VOTC regions across individuals (e.g., Zhen et al. 2015).

Finally, while "neuronal recycling" is a loaded and (in this case) misleading terminology, neural competition is, in contrast, ubiquitous in the central nervous system and appears fundamental for neural plasticity and selectivity (Edelman 1987; Merzenich et al. 1988). For instance, competition for representation has been well characterized in different animal species at the level of the somatosensory cortex (e.g., for inputs from different fingers; Merzenich et al. 1988), the primary auditory cortex (e.g., for different frequency sounds; Zhang et al. 2003) and the primary visual cortex (e.g., visual field and ocular dominance; Antonini and Stryker 2003; El-Boustani et al. 2018). Collectively, these studies have shown that sensory inputs that are actively enhanced (due to extensive experience/ training) or suppressed (due to denervation for instance), increase or shrink in terms of cortical representations relative to competing sensory inputs with similar functional properties. Importantly, this neuronal competition depends on inherent overlap of terminating neuronal fibers and a fine balance of inhibitory-excitatory connections between cortical columns (Buanomano and Merzenich 1998). Despite the unconvincing evidence reviewed here at a large-scale level in support of direct neural competition between faces and letter strings in the human VOTC, it would be extremely exciting if such fundamental neural competition principles could be generalized to high-level visual representations in these cortical regions in future research.

Acknowledgements This work was supported by a LUE (Lorraine Université d'Excellence) program, a 2018 project from the Région Grand Est and Face perception INTER project (INTER/FNRS/15/11015111) funded by the Luxembourgish Fund for Scientific Research (FNR, Luxembourg) and by the Belgian Funds for Scientific Research (FNRS; Grant nr: PDR T.0207.16 FNRS). The authors thank Talia Retter, Simen Hagen and three anonymous reviewers for their helpful comments on previous versions of this manuscript.

Author contributions BR initiated this review, BR and AL performed literature search, drafted and critically revised the work. 
Availability of data and material Non applicable (review paper, no new data reported or material used).

Code availability Non applicable (review paper, no codes developed).

\section{Declarations}

Conflict of interest The authors declare no competing conflict of interest.

Ethics approval Non applicable (review paper).

\section{References}

Adibpour P, Dubois J, Dehaene-Lambertz G (2018) Right but not left hemispheric discrimination of faces in infancy. Nat Hum Behav 2:67-79

Allison T, Ginter H, McCarthy et al (1994) Face recognition in human extrastriate cortex. J Neurophysiol 71:821-825

Antonini A, Stryker MP (2003) Rapid remodeling of axonal arbors in the visual cortex. Science 260:1819-1821

Badzakova-Trajkov G, Häberling IS, Roberts RP, Corballis MC (2010) Cerebral asymmetries: complementary and independent processes. PLoS ONE 5(3):e9682

Balas B, Saville A (2015) N170 face specificity and face memory depend on hometown size. Neuropsychologia 69:211-217

Balas B, Saville A (2017) Hometown size affects the processing of naturalistic face variability. Vis Res 141:228-236

Barton JJ (2008) Structure and function in acquired prosopagnosia: lessons from a series of 10 patients with brain damage. J Neuropsychol 2:197-225

Bedny M (2017) Evidence from blindness for a cognitively pluripotent cortex. Trends Cogn Sci 21:637-648

Behrmann M, Avidan G (2005) Congenital prosopagnosia: face-blind from birth. Trends Cogn Sci 9:180-187

Behrmann M, Plaut DC (2015) A vision of graded hemispheric specialization. Ann NY Acad Sci 1359:30-46

Behrmann M, Plaut DC (2020) Hemispheric organization for visual object recognition: a theoretical account and empirical evidence. Perception 49:373-404

Bentin S, Allison T, Puce A, Perez E, McCarthy G (1996) Electrophysiological studies of face perception in humans. J Cogn Neurosci 8:551-565

Benton AL, Van Allen MW (1968) Impairment in facial recognition in patients with cerebral disease. Trans Am Neurol Assoc 93:38-42

Bodamer J (1947) Die Prosopagnosie. Archiv Fur Psychiatrie Und Zeitschrift Fur Neurologie 179:6-54

Bogen JE (1969) The other side of the brain. II. An appositional mind. Bull Los Angeles Neurol Soc 34:135-136

Boles DB (1984) Global versus local processing: is there a hemispheric dichotomy? Neuropsychologia 22:445-545

Bolger DJ, Perfetti CA, Schneider W (2005) Cross-cultural effect on the brain revisited: universal structures plus writing system variation. Hum Brain Mapp 2:92-104

Bötzel K, Grüsser OJ (1989) Electric brain potentials evoked by pictures of faces and non-faces: a search for "face-specific" EEG-potentials. Exp Brain Res 77:349-360

Bouhali F, de Schotten TM, Pinel P, Poupon C, Mangin J-F, Dehaene S, Cohen L (2014) Anatomical connections of the visual word form area. J Neurosci 34:15402-15414
Bouvier SE, Engel SA (2006) Behavioral deficits and cortical damage loci in cerebral achromatopsia. Cereb Cortex 16:183-191

Bradshaw JL, Nettleton NC (1981) The nature of hemispheric specialization in man. Behav Brain Sci 4:51-63

Braga LW, Amemiya E, Tauil A, Suguieda D, Lacerda C, Klein E, Dehaene-Lambertz G, Dehaene S (2017) Tracking adult literacy acquisition with functional MRI: a single-case study. Mind Brain Educ 11:121-132

Brederoo SG, Van der Haegen L, Brysbaert M, Nieuwenstein MR, Cornelissen FW, Lorist MM (2020) Towards a unified understanding of lateralized vision: a large-scale study investigating principles governing patterns of lateralization using a heterogeneous sample. Cortex 133:201-214

Broca P (1865) Sur le siège de la faculté du langage articulé. Bull Mém Soc Anthropol Paris 6:377-393

Bruce V, Young A (1998) In the eye of the beholder: the science of face perception. Oxford University Press, New York

Bukowski H, Dricot L, Hanseeuw B, Rossion B (2013) Cerebral lateralization of face-sensitive areas in left-handers: only the FFA does not get it right. Cortex 49:2583-2589

Buonomano DV, Merzenich MM (1998) Cortical plasticity: from synapses to maps. Annu Rev Neurosci 21:149-186

Busigny T, Rossion B (2011) Holistic processing impairment can be restricted to faces in acquired prosopagnosia: evidence from the global/local Navon effect. J Neuropsychol 5(Pt 1):1-14

Cai Q, Lavidor M, Brysbaert M, Paulignan Y, Nazir TA (2008) Cerebral lateralization of frontal lobe language processes and lateralization of the posterior visual word processing system. J Cogn Neurosci 20:672-681

Cai Q, Paulignan Y, Brysbaert M, Ibarrola D, Nazir TA (2010) The left ventral occipito-temporal response to words depends on language lateralization but not on visual familiarity. Cereb Cortex 20:1153-1163

Canário N, Jorge L, Castelo-Branco M (2020) Distinct mechanisms drive hemispheric lateralization of object recognition in the visual word form and fusiform face areas. Brain Lang 210(August): 104860

Cantlon JF, Pinel P, Dehaene S, Pelphrey KA (2011) Cortical representations of symbols, objects, and faces are pruned back during early childhood. Cereb Cortex 21(1):191-199

Cao X, Yang Q, Zhong P, Chen C (2019) The characteristics of face configural effect in illiterates and literates. Acta Physiol (oxf) 201:0-5

Carey S (1981) The development of face perception. In: Davies G, Ellis HD (eds) Perceiving and remembering faces. Academic Press

Carey S (1992) Becoming a face expert. Philos Trans R Soc Lond B Biol Sci 335(1273):95-102 (discussion 102-3)

Carey S, Diamond R (1977) From piecemeal to configurational representation of faces. Science 195:312-314

Carreiras M, Seghier ML, Baquero S, Estévez A, Lozano A, Devlin JT, Price CJ (2009) An anatomical signature for literacy. Nature 461:983-986

Castro-Caldas A, Cavaleiro Miranda P, Carmo I, Reis A, Leote F, Ribeiro C, Ducla-Soares E (1999) Influence of learning to read and write on the morphology of the corpus callosum. Eur J Neurol 6:23-28

Centanni TM, Norton ES, Park A, Beach SD, Halverson K, OzernovPalchik O, Gaab N, Gabrieli J (2018) Early development of letter specialization in left fusiform is associated with better word reading and smaller fusiform face area. Dev Sci 21(5):e12658

Chance SA, Sawyer EK, Clover LM et al (2013) Hemispheric asymmetry in the fusiform gyrus distinguishes Homo sapiens from chimpanzees. Brain Struct Funct 218:1391-1405

Cohen L, Dehaene S (2004) Specialization within the ventral stream the case for the visual word form area. Neuroimage 22:466-476 
Cohen L, Dehane S, Naccache L, Lehériciy S, Dehane-Lambertz G, Hénaff MA, Michel F (2000) The visual word form area: spatial and temporal characterization of an initial stage of reading in normal subjects and posterior split-brain patients. Brain 123:291-307

Cohen L, Lehéricy S, Chochon F, Lemer C, Rivaud S, Dehaene S (2002) Language-specific tuning of visual cortex? Functional properties of the Visual Word Form Area. Brain 125(Pt 5):1054-1069

Cohen AL, Soussand L, Corrow SL, Martinaud O, Barton JJS, Fox MD, Cohen AL (2019) Looking beyond the face area: lesion network mapping of prosopagnosia. Brain J Neurol 142:3975-3990

Cohen Kadosh K, Cohen Kadosh R, Dick F, Johnson MH (2011) Developmental changes in effective connectivity in the emerging core face network. Cereb Cortex 21:1389-1994

Corballis MC (1983) Human laterality. Academic Press, New York

Corballis M, Morgan M (1978) On the biological basis of human laterality: I. Evidence for a maturational left-right gradient. Behav Brain Sci 1(2):261-269

Corballis MC (1991) The lopsided ape. Oxford University Press, New York

Crookes K, McKone E (2009) Early maturity of face recognition: no childhood development of holistic processing, novel face encoding, or face-space. Cognition 111:219-247

Dahl CD, Rasch MJ, Tomonaga M, Adachi I (2013) The face inversion effect in non-human primates revisited-an investigation in chimpanzees (Pan troglodytes). Sci Rep 3:2504

Damasio AR, Damasio H, Van Hoesen GW (1982) Prosopagnosia: anatomic basis and behavioral mechanisms. Neurology 32:331-341

Davies-Thompson J, Tashakkor AY, Barton JJS (2016) The relationship between visual word and face processing lateralization in the fusiform gyri: a cross-sectional study. Brain Res 1644:88-97

Déjerine J (1891) Sur un cas de cécité verbale avec agraphie, suivi d'autopsie. In: Mémoires Société Biologique

de Haan M, Nelson CA (1999) Brain activity differentiates face and object processing in 6-month-old infants. Dev Psychol 35:1113-1121

de Heering A, Rossion B (2015) Rapid categorization of natural face images in the infant right hemisphere. Elife 4:1-14

de Schonen S, Mathivet E (1989) First come, first served: a scenario about the development of hemispheric specialization in face recognition during infancy. Cahiers De Psychologie Cognitive Curr Psychol Cogn 9(1):3-44

de Schonen S, Mathivet E (1990) Hemispheric asymmetry in a face discrimination task in infants. Child Dev 61:1192-1205

de Haan M, Johnson MH, Halit H (2003) Development of face-sensitive event-related potentials during infancy: a review. Int J Psychophysiol 51:45-58

de Heering A, de Liedekerke C, Deboni M, Rossion B (2010) The role of experience during childhood in shaping the other-race effect. Dev Sci 13:181-187

de Heering A, Rossion B, Maurer D (2012) Developmental changes in face recognition during childhood: evidence from upright and inverted faces. Cogn Dev 27:17-27

de Moraes R, de Sousa BM, Fukusima S (2014) Hemispheric specialization in face recognition: from spatial frequencies to holistic/ analytic cognitive processing. Psychol Neurosci 7:503-511

De Renzi E (1986) Prosopagnosia in two patients with CT scan evidence of damage confined to the right hemisphere. Neuropsychologia 24:385-389

De Renzi E, Faglioni P, Grossi D, Nichelli P (1991) Apperceptive and associative forms of prosopagnosia. Cortex 27:213-221

de Schonen S, Gil de Diaz M, Mathivet E (1986) Hemispheric asymetry in face processing in infancy. In: Ellis HD, Jeeves MA, Newcombe F, Young A (eds) Aspects of face processing. Martinus Nijhof Publishers
Deen B, Richardson H, Dilks DD, Takahashi A, Keil B, Wald LL, Kanwisher N, Saxe R (2017) Organization of high-level visual cortex in human infants. Nat Commun 8:13995

Dehaene S, Cohen L (2007) Cultural recycling of cortical maps. Neuron 56:384-398

Dehaene S, Pegado F, Braga LW, Ventura P, Nunes Filho G, Jobert A, Dehaene-Lambertz G, Kolinsky R, Morais J, Cohen L (2010) How learning to read changes the cortical networks for vision and language. Science 330:1359-1364

Dehaene S, Cohen L, Morais J, Kolinsky R (2015) Illiterate to literate: behavioural and cerebral changes induced by reading acquisition. Nature 16:234-244

Dehaene-Lambertz G, Dehaene S, Hertz-Pannier L (2002) Functional neuroimaging of speech perception in infants. Science 298:2013-2015

Dehaene-Lambertz G, Monzalvo K, Dehaene S (2018) The emergence of the visual word form: longitudinal evolution of category-specific ventral visual areas during reading acquisition. PLoS Biol 16(3):e2004103

Delis DC, Robertson LC, Efron R (1986) Hemispheric specialization of memory for visual hierarchical stimuli. Neuropsychologia 24:205-214

Devlin JT, Jamison HL, Gonnerman LM, Matthews PM (2006) The role of the posterior fusiform gyrus in reading. J Cogn Neurosci 18:911-922

DiCarlo JJ, Cox DD (2007) Untangling invariant object recognition. Trends Cogn Sci 11:333-341

Doty RW, Fei R, Hu S, Kavcic V (1999) Long-term reversal of hemispheric specialization for visual memory in a split-brain macaque. Behav Brain Res 102:99-114

Duchaine B, Nakayama K (2006) The Cambridge Face Memory Test: results for neurologically intact individuals and an investigation of its validity using inverted face stimuli and prosopagnosic participants. Neuropsychologia 44:576-585

Duchaine B, Yovel G (2015) A revised neural framework for face processing. Annu Rev vis Sci 1:393-416

Dundas EM, Plaut DC, Behrmann M (2012) The joint development of hemispheric lateralization for words and faces. J Exp Psychol Gen 142:348-358

Dundas EM, Plaut DC, Behrmann M (2014) An ERP investigation of the co-development of hemispheric lateralization of face and word recognition. Neuropsychologia 61:315-323

Dundas EM, Plaut DC, Behrmann M (2015) Variable left-hemisphere language and orthographic lateralization reduces righthemisphere face lateralization. J Cogn Neurosci 27:913-925

Edelman GM (1987) Neural Darwinism: the theory of neuronal group selection. Basic Books, New York

Edelman GM, Finkel LH (1985) Neuronal group selection in the cerebral cortex. In: Gall E, Edelman G (eds) Dynamic aspects of neorcortical function. Wiley, New York, pp 653-695

Eimer M, McCarthy RA (1999) Prosopagnosia and structural encoding of faces: evidence from event- related potentials. NeuroReport $5: 255-259$

Ekstrand C, Neudorf J, Kress S, Borowsky R (2020) Structural connectivity predicts functional activation during lexical and sublexical reading. Neuroimage 218:117008

Elbich DB, Molenaar PCM, Scherf KS (2019) Evaluating the organizational structure and specificity of network topology within the face processing system. Hum Brain Mapp 40:2581-2595

El-Boustani IP, Breton-Provencher JPK, Knott V, Okuno GW, Bito H (2018) Locally coordinated synaptic plasticity of visual cortex neurons in vivo. Science 360:1349-1354

Ellis HD (1983) The role of the right hemisphere in face perception. In: Young AW (ed) Functions of the right cerebral hemisphere. Academic Press, London, pp 33-64 
Fan C, Chen S, Zhang L, Qi Z, Jin Y, Wang Q, Luo Y, Li H, Luo W (2015) NeuroImage N170 changes reflect competition between faces and identifiable characters during early visual processing. Neuroimage 110:32-38

Farah MJ (1990/2004) Visual agnosia, 2nd edn. MIT Press, Cambridge

Farah MJ (1991) Patterns of co-occurrence among the associative agnosias: implications for visual object recognition. Cogn Neuropsychol 8:1-19

Farah MJ, Wilson KD, Drain M, Tanaka JN (1998) What is "special" about face perception? Psychol Rev 105:482-498

Feng X, Monzalvo K, Dehaene S, Dehaene-Lambertz G (2021) Evolution of reading and face circuits during the first three years of reading acquisition. Preprint. https://doi.org/10.31234/osf.io/ e7vhm

Fernandes T, Leite I, Kolinsky R (2016) Into the looking glass: literacy acquisition and mirror invariance in preschool and first-grade children. Child Dev 87:2008-2025

Fernandes T, Arunkumar M, Huettig F (2021) The role of the written script in shaping mirror-image discrimination: evidence from illiterate, Tamil literate, and Tamil-Latin-alphabet bi-literate adults. Cognition 206:104493

Frässle S, Paulus FM, Krach S, Jansen A (2016a) Test-retest reliability of effective connectivity in the face perception network. Hum Brain Mapp 37:730-744

Frässle S, Krach S, Paulus FM, Jansen A (2016b) Handedness is related to neural mechanisms underlying hemispheric lateralization of face processing. Sci Rep 6:27153

Fu S, Chen Y, Smith S, Iversen S, Matthews PM (2002) Effects of word form on brain processing of written Chinese. Neuroimage $17: 1538-1548$

Gabay Y, Dundas E, Plaut D, Behrmann M (2017) Atypical perceptual processing of faces in developmental dyslexia. Brain Lang 173:41-51

Gao X, Gentile F, Rossion B (2018) Fast periodic stimulation (FPS): a highly effective approach in fMRI brain mapping. Brain Struct Funct 223:2433-2454

Gao X, Vuong QC, Rossion B (2019) The cortical face network of the prosopagnosic patient PS with fast periodic stimulation in fMRI. Cortex 119:528-542

Gathers AD, Bhatt R, Corbly CR, Farley AB, Joseph JE (2004) Developmental shifts in cortical loci for face and object recognition. NeuroReport 15:1549-1553

Gazzaniga M (1967) The split brain in man. Sci Am 217:24-29

Gazzaniga MS, LeDoux JE (1978) The integrated mind. Plenum Press

Gazzaniga MS, Bogen JE, Sperry RW (1965) Observations on visual perception after disconnexion of the cerebral hemispheres in man. Brain 88:221-236

Germine LT, Duchaine B, Nakayama K (2011) Where cognitive development and aging meet: face learning ability peaks after age 30 . Cognition 118:201-210

Gerrits R, Van der Haegen L, Brysbaert M, Vingerhoets G (2019) Laterality for recognizing written words and faces in the fusiform gyrus covaries with language dominance. Cortex 117:196-204

Geschwind N, Levitsky W (1968) Human brain left-right asymmetries in temporal speech region. Science 161:186-187

Gilbert C, Bakan P (1973) Visual asymmetry in perception of faces. Neuropsychologia 11:355-362

Glezer LS, Jiang X, Riesenhuber M (2009) Report evidence for highly selective neuronal tuning to whole words in the "visual word form area." Neuron 62:199-204

Glezer LS, Kim J, Rule J, Jiang X, Riesenhuber M (2015) Adding words to the brain's visual dictionary: novel word learning selectively sharpens orthographic representations in the VWFA. J Neurosci 35:4965-4972
Gliga T, Dehaene-Lambertz G (2007) Development of a view-invariant representation of the human head. Cognition 102:261-288

Goffaux V, Peters J, Haubrechts J, Schiltz C, Jansma B, Goebel R (2011) From coarse to fine? Spatial and temporal dynamics of cortical face processing. Cereb Cortex 21:467-476

Golarai G, Ghahremani DG, Whitfield-Gabrieli S, Reiss A, Eberhardt JL, Gabrieli JDE, Grill-Spector K (2007) Differential development of high-level visual cortex correlates with category-specific recognition memory. Nat Neurosci 10:512-522

Gomez J, Natu V, Jeska B, Barnett M, Grill-Spector K (2018) Development differentially sculpts receptive fields across early and high-level human visual cortex. Nat Commun 9:1-12

Goren CC, Sarty M, Wu EYK (1975) Visual following and pattern discrimination of face-like stimuli by newborn infants. Pediatrics 56:544-549

Gotts SH, Joon J, Wallace GL, Ziad S, Saad RWC, Martin A (2013) Two distinct forms of functional lateralization in the human brain. Proc Natl Acad Sci 110:E3435-E3444

Grill-Spector K, Weiner KS (2014) The functional architecture of the ventral temporal cortex and its role in categorization. Nat Rev Neurosci 15(8):536-548

Grill-Spector K, Weiner KS, Kay K, Gomez J (2017) The functional neuroanatomy of human face perception. Annu Rev vis Sci 3:167-196

Hagen S, Jacques C, Maillard L, Colnat-Coulbois S, Rossion B, Jonas J (2020) Spatially dissociated intracerebral maps for face- and house-selective activity in the human ventral occipito-temporal cortex. Cereb Cortex 30:4026-4043

Hagen S, Lochy A, Jacques C, Maillard L, Colnat-Coulbois S, Rosson B (2021) Dissociated face-and word-selective intracerebral responses in the human ventral occipito-temporal cortex. bioRxiv https://doi.org/10.1101/2020.12.23.423819

Halgren E, Baudena P, Heit G, Clarke M, Marinkovic K (1994) Spatiotemporal stages in face and word processing. 1. Depth recorded potentials in the human occipital and parietal lobes. J Physiol $88: 1-50$

Hamilton CR, Vermeire BA (1983) Discrimination of monkey faces by split-brain monkeys. Behav Brain Res 9:263-275

Hamilton CR, Vermeire BA (1988) Cognition, not handedness, is lateralized in monkeys. Behav Brain Sci 11(4):723-725

Hannagan T, Amedi A, Cohen L, Dehaene-Lambertz G, Dehaene S (2015) Origins of the specialization for letters and numbers in ventral occipitotemporal cortex. Trends Cogn Sci 19:374-382

Harris A, Aguirre GK (2010) Neural tuning for face wholes and parts in human fusiform gyrus revealed by FMRI adaptation. J Neurophysiol 104:336-345

Hasson U, Levy I, Behrmann M, Hendler T, Malach R (2002) Centerbiased representation for characters in the human ventral visual stream. Neuron 34:479-490

Haxby JV, Hoffman EA, Gobbini MI (2000) The distributed human neural system for face perception. In: Trends in cognitive sciences

Hecaen H, Angelergues R (1962) Agnosia for faces (prosopagnosia). Arch Neurol 7:92-100

Hellige JB (1993) Perspectives in cognitive neuroscience. Hemispheric asymmetry. What's right and what's left. . Harvard University Press

Hellige JB, Sergent J (1986) Role of task factors in visual field asymmetries. Brain Cogn 5:200-222

Hervais-Adelman A, Kumar U, Mishra RK, Tripathi VN, Guleria A, Singh JP, Eisner F, Huettig F (2019) Learning to read recycles visual cortical networks without destruction. Sci Adv 5(9):eaax0262. https://doi.org/10.1126/sciadv.aax0262

Hildesheim FE, Debus I, Kessler R, Thome I, Zimmermann KM, Steinsträter O, Sommer J, Kamp-Becker I, Stark R (2020) The 
trajectory of hemispheric lateralization in the core system of face processing: a cross-sectional functional magnetic resonance imaging pilot study. Front Psychol 11:507199

Hillger LA, Koenig O (1991) Separable mechanisms in face processing: evidence from hemispheric specialization. J Cogn Neurosci 3(1):42-58

Hillis AE, Kane A, Barker P, Beauchamp N, Wityk R (2001) Neural substrates of the cognitive processes underlying reading: evidence from magnetic resonance perfusion imaging in hyperacute stroke. Aphasiology 15:919-931

Hillis AE, Newhart M, Heidler J, Barker P, Herskovits E, Degaonkar M (2005) The roles of the "visual word form area" in reading. Neuroimage 24:548-559

Hills PJ, Lewis MB (2018) The development of face expertise: evidence for a qualitative change in processing. Cogn Dev 48:1-18

Hirshorn EA, Wrencher A, Durisko C, Moore MW, Fiez JA (2016) Fusiform gyrus laterality in writing systems with different mapping principles: an artificial orthography training study. J Cogn Neurosci 28:882-894

Huettig F, Mishra RK (2014) How literacy acquisition affects the illiterate mind - a critical examination of theories and evidence. Lang Linguist Compass 8:401-427

Huettig F, Kolinsky R, Lachmann T (2018) The culturally co-opted brain: how literacy affects the human mind. Lang Cogn Neurosci 33:275-277

Itier RJ, Taylor MJ (2004) Effects of repetition and configural changes on the development of face recognition processes. Dev Sci 7(4):469-487

Ivry R, Robertson LC (1998) The two sides of perception. MIT Press, London

Jacobs RA, Jordan MI (1992) Computational consequences of a bias toward short connections. J Cogn Neurosci 4:323-336

Jacques C, Rossion B (2004) Concurrent processing reveals competition between visual representations of faces. NeuroReport 15:2417-2421

Jacques C, Rossion B (2009) The initial representation of individual faces in the right occipito-temporal cortex is holistic: electrophysiological evidence from the composite face illusion. $\mathbf{J}$ vis 9(6):8-16

Jacques C, Rossion B, Volfart A, Brissart H, Colnat-Coulbois S, Maillard L, Jonas J (2020) The neural basis of rapid unfamiliar face individuation with human intracerebral recordings. Neuroimage 221:117174

Jeffreys DA (1989) A face-responsive potential recorded from the human scalp. Exp Brain Res 78:193-202

Johnson MH, Dziurawiec S, Ellis HD, Morton J (1991) Newborns' preferential tracking of faces and its subsequent decline. Cognition 40:1-19

Jonas J, Rossion B (2021) Intracerebral electrical stimulation to understand the neural basis of human face identity recognition. Eur $\mathbf{J}$ Neurosci. https://doi.org/10.1111/ejn.15235

Jonas J, Descoins M, Koessler L, Colnat-Coulbois S, Sauvee M, Guye M, Vignal J-P, Vespignani H, Rossion B, Maillard L (2012) Focal electrical intracerebral stimulation of a face-sensitive area causes transient prosopagnosia. Neuroscience 222:281-288

Jonas J, Jacques C, Liu-Shuang J, Brissart H, Colnat-Coulbois S, Maillard L, Rossion B (2016) A face-selective ventral occipitotemporal map of the human brain with intracerebral potentials. Proc Natl Acad Sci USA 113:E4088-E4097

Joseph JE, Gathers AD, Bhatt RS (2011) Progressive and regressive developmental changes in neural substrates for face processing: testing specific predictions of the Interactive Specialization account. Dev Sci 14:227-241
Joyce C, Rossion B (2005) The face-sensitive N170 and VPP components manifest the same brain processes: The effect of reference electrode site. Clin Neurophysiol 116:2613-2631

Kanwisher N, Yovel G (2006) The fusiform face area: a cortical region specialized for the perception of faces. Philos Trans R Soc Lond B Biol Sci 361:2109-2128

Kanwisher N, McDermott J, Chun MM (1997) The fusiform face area: a module in human extrastriate cortex specialized for face perception. J Neurosci 17:4302-4311

Kim KH, Yoon HW, Park HW (2004) spatiotemporal brain activation pattern during word/picture perception by native Koreans. Cogn Neurosci Neuropsychol 15:7

Knecht S, Deppe M, Dräger B, Bobe L, Lohmann H, Ringelstein E, Henningsen $H$ (2000) Language lateralization in healthy righthanders. Brain 123:74-81

Kolb B, Milner B, Taylor L (1983) Perception of faces by patients with localized cortical excisions. Can J Psychol Revue Canadienne De Psychologie 37:8-18

Kolinsky R, Fernandes T (2014) A cultural side effect: learning to read interferes with identity processing of familiar objects. Front Psychol 5:1224

Kolinsky R, Verhaeghe A, Fernandes T, Mengarda EJ, Grimm-Cabral L, Morais J (2011) Enantiomorphy through the looking glass: literacy effects on mirror-image discrimination. J Exp Psychol Gen 140:210-238

Kriegeskorte N, Mur M, Bandettini P (2008) Representational similarity analysis: connecting the branches of systems neuroscience. Front Syst Neurosci 2:4. https://doi.org/10.3389/neuro.06.004. 2008

Kronbichler M, Hutzler F, Wimmer H, Mair A, Staffen W, Ladurner G (2004) The visual word form area and the frequency with which words are encountered: evidence from a parametric fMRI study. Neuroimage 21:946-953

Kubota EC, Joo SJ, Huber E, Yeatman JD (2019) Word selectivity in high-level visual cortex and reading skill. Dev Cogn Neurosci 36:100593

Kuefner D, de Heering A, Jacques C, Palmero-Soler E, Rossion B (2010) Early visually evoked electrophysiological responses over the human brain (P1, N170) show stable patterns of face-sensitivity from 4 years to adulthood. Front Hum Neurosci 3(January):67. https://doi.org/10.3389/neuro.09.067.2009

Kühn CD, Wilms IL, Dalrymple KA, Gerlach C, Starrfelt R (2021) Face recognition in beginning readers: investigating the potential relationship between reading and face recognition during the first year of school. Vis Cogn 0(0):1-12

Lamb MR, Robertson LC, Knight RT (1989) Attention and interference in the processing of hierarchical patterns: inferences from patients with right and left temporal-parietal lesions. Neuropsychologia 27:471-548

Lamb MR, Robertson LC, Knight RT (1990) Component mechanisms underlying the processing of hierarchically organized patterns: inferences from patients with unilateral cortical lesions. J Exp Psychol Learn Mem Cogn 16:471-483

Landis T, Cummings JL, Christen L, Bogen JE, Imhof HG (1986) Are unilateral right posterior cerebral lesions sufficient to cause prosopagnosia? Clinical and radiological findings in six additional patients. Cortex 22:243-252

LeDoux J (1983) Cerebral asymmetry and the integrated function of the brain. In Young AW (ed) Functions of the right hemisphere. Academic Press, New York, pp 203-216

Le Grand R, Mondloch CJ, Maurer D, Brent HP (2003) Expert face processing requires visual input to the right hemisphere during infancy. Nat Neurosci 6:1108-1112

Leleu A, Rekow D, Poncet F, Schaal B, Durand K, Rossion B, Baudouin J-Y (2020) Maternal odor shapes rapid face categorization in the infant brain. Dev Sci 23:e12877 
Lerma-Usabiaga G, Carreiras M, Paz-Alonso PM (2018) Converging evidence for functional and structural segregation within the left ventral occipitotemporal cortex in reading. Proc Natl Acad Sci USA 115:E9981-E9990

Levine D, Calvanio R (1989) Prosopagnosia: a defect in visual configural processing. Brain Cogn 10:149-170

Levy J, Trevarthen C, Sperry RW (1972) Perception of bilateral chimeric figures following hemispheric deconnexion. Brain 95:61-78

Lhermitte F, Chain F, Escourolle R, Ducarne B, Pillon B (1972) Anatomical study of a case of prosopagnosia. Rev Neurol (paris) 126(5):329-346

Li S, Lee K, Zhao J, Yang Z, He S, Weng X (2013) Neural competition as a developmental process: early hemispheric specialization for word processing delays specialization for face processing. Neuropsychologia 51:950-959

Li J, Osher DE, Hansen HA, Saygin Z (2020) Innate connectivity patterns drive the development of the visual word form area. Sci Rep 10(1):1-13

Liu C, Zhang WT, Tang YY, Mai XQ, Chen HC, Tardif T, Luo YJ (2008) The Visual Word Form Area: evidence from an fMRI study of implicit processing of Chinese characters. Neuroimage 40:1350-1361

Liu-Shuang J, Norcia AM, Rossion B (2014) An objective index of individual face discrimination in the right occipito-temporal cortex by means of fast periodic oddball stimulation. Neuropsychologia 52:57-72

Lochy A, Van Belle G, Rossion B (2015) A robust index of lexical representation in the left occipitotemporal cortex as evidenced by EEG responses to fast periodic visual stimulation. Neuropsychologia 66:18-31

Lochy A, Van Reybroeck M, Rossion B (2016) Left cortical specialization for visual letter strings predicts rudimentary knowledge of letter-sound association in preschoolers. Proc Natl Acad Sci USA 113(30):8544-8549

Lochy A, Jacques C, Maillard L, Colnat-Coulbois S, Rossion B, Jonas J (2018) Selective visual representation of letters and words in the left ventral occipito-temporal cortex with intracerebral recordings. Proc Natl Acad Sci USA 115(32):E7595-E7604

Lochy A, de Heering A, Rossion B (2019) The non-linear development of the right hemispheric specialization for human face perception. Neuropsychologia 126:10-19

Lochy A, Schiltz C, Rossion B (2020) The right hemispheric dominance for face perception in preschool children depends on the visual discrimination level. Dev Sci 23:1-16

Malik-Moraleda S, Orihuela K, Carreiras M, Duñabeitia JA (2018) The consequences of literacy and schooling for parsing strings. Lang Cogn Neurosci 33:293-299

Mandler G (1980) Recognizing: the judgment of previous occurrence. Psychol Rev 87:252-271

Martelli M, Majaj NJ, Pelli DG (2005) Are faces processed like words? A diagnostic test for recognition by parts. J vis 5(1):58-70

Martin A, Schurz M, Kronbichler M, Richlan F (2015) Reading in the brain of children and adults: a meta-analysis of 40 functional magnetic resonance imaging studies. Hum Brain Mapp 36:1963-1981

Martin L, Durisko C, Moore MW, Coutanche MN, Chen D, Fiez JA (2019) The VWFA is the home of orthographic learning when houses are used as letters. Eneuro. https://doi.org/10.1523/ ENEURO.0425-17.2019

Mattson AJ, Levin HS, Grafman J (2000) A case of prosopagnosia following moderate closed head injury with left hemisphere focal lesion. Cortex 36:125-137
Maurer U, Brem S, Kranz F, Bucher K, Benz R, Halder P, Steinhausen $\mathrm{HC}$, Brandeis D (2006) Coarse neural tuning for print peaks when children learn to read. Neuroimage 33:749-758

McCandliss BD, Cohen L, Dehaene S (2003) The visual word form area: expertise for reading in the fusiform gyrus. Trends Cogn Sci 7:293-299

McCarthy G, Puce A, Gore JC, Allison T (1997) Face-specific processing in the Human fusiform gyrus. J Cogn Neurosci 9:605-610

McKone E, Crookes K, Jeffery L, Dilks DD (2012) A critical review of the development of face recognition: experience is less important than previously believed. Cogn Neuropsychol 29(1-2):174-212

Meadows JC (1974) The anatomical basis of prosopagnosia. J Neurol Neurosurg Psychiatry 37:489-501

Meng M, Cherian T, Singal G, Sinha P (2012) Lateralization of face processing in the human brain. Proc Biol Sci 279:2052-2061

Merzenich M, Recanzone G, Jenkins WM, Allard TT, Nudo RJ (1988) Cortical representational plasticity. In: Rakic P, Singer W (eds) Neurobiology of neo-cortex. Wiley, New York, pp 41-67

Monzalvo K, Fluss J, Billard C, Dehaene S, Dehaene-lambertz G (2012) Cortical networks for vision and language in dyslexic and normal children of variable socio-economic status. Neuroimage 61:258-274

Moore MW, Durisko C, Perfetti CA, Fiez JA (2014) Learning to read an alphabet of human faces produces left-lateralized training effects in the fusiform gyrus. J Cogn Neurosci 26:896-913

Morrison DJ, Schyns PG (2001) Usage of spatial scales for the categorization of faces, objects, and scenes. Psychon Bull Rev 8:454-469

Näsänen R (1999) Spatial frequency bandwidth used in the recognition of facial images. Vis Res 39(23):3824-3833

Natu VS, Barnett MA, Hartley J, Gomez J, Stigliani A, Grill-Spector K (2016) Development of neural sensitivity to face identity correlates with perceptual discriminability. J Neurosci 36:10893-10917

Navon D (1977) Forest before trees: the precedence of global features in visual perception. Cogn Psychol 9:353-438

Nestor A, Behrmann M, Plaut DC (2013) The neural basis of visual word form processing: a multivariate investigation. Cereb Cortex 23:1673-1684

Newcombe F, de Haan EHF, Ross J, Young AW (1989) Face processing, laterality and contrast sensitivity. Neuropsychologia 27:523-538

Norcia AM, Appelbaum LG, Ales JM, Cottereau BR, Rossion B (2015) The steady-state visual evoked potential in vision research: a review. J vis $15(6): 1-46$

Nordt M, Gomez J, Natu VS et al (2021) Cortical recycling in highlevel visual cortex during childhood development. Nat Hum Behav (2021). https://doi.org/10.1038/s41562-021-01141-5

Olulade OA, Flowers DL, Napoliello EM, Eden GF (2013) Developmental differences for word processing in the ventral stream. Brain Lang 125:134-145

Olulade A, Seydell-Greenwald A, Chambers CE, Turkeltaub PE, Dromerick AW, Berl MM, Gaillard WD, Newport EL (2020) The neural basis of language development: changes in lateralization over age. Proc Natl Acad Sci USA 117:23477-23483

Orihuela KB, Carreiras M, Dunabeita JA (2013) Does literacy change face recognition? In: Poster presented at 54th annual meeting of the Psychonomic Society, Toronto, November

Ossowski A, Behrmann M (2015) Left hemisphere specialization for word reading potentially causes, rather than results from, a left lateralized bias for high spatial frequency visual information. Cortex 72:27-39

Otsuka Y (2014) Face recognition in infants: a review of behavioral and near-infrared spectroscopic studies. Jpn Psychol Res 56:76-90 
Overman WH, Doty RW (1982) Hemispheric specialization displayed by man but not macaques for analysis of faces. Neuropsychologia 20:113-128

Packheiser J, Pusch R, Stein CC, Güntürkün O, Lachnit H, Uengoer MQ (2020) How competitive is cue competition? J Exp Psychol 73:104-114

Parkin AJ, Williamson P (1987) Cerebral lateralisation at different stages of facial processing. Cortex 23(1):99-110

Peelen MV, Glaser B, Vuilleumier P, Eliez S (2009) Differential development of selectivity for faces and bodies in the fusiform gyrus. Dev Sci 12:F16-F25

Pegado F, Comerlato E, Ventura F, Jobert A, Nakamura K, Buiatti M, Ventura P, Dehaene-Lambertz G, Kolinsky R, Morais J, Braga LW, Cohen L, Dehaene S (2014a) Timing the impact of literacy on visual processing. Proc Natl Acad Sci USA 111:E5233-E5242

Pegado F, Nakamura K, Braga LW, Ventura P, Nunes Filho G, Pallier C, Jobert A, Morais J, Cohen L, Kolinsky R, Dehaene S (2014b) Literacy breaks mirror invariance for visual stimuli: a behavioral study with adult illiterates. J Exp Psychol Gen 143:887-894

Peirce JW, Kendrick KM (2002) Functional asymmetry in sheep temporal cortex. NeuroReport 13:2395-2399

Peirce JW, Leigh AE, Kendrick KM (2001) Configurational coding, familiarity and the right hemisphere advantage for face recognition in sheep. Neuropsychologia 38:475-483

Perfetti CA (1992) The representation problem in reading acquisition. Reading acquisition. Lawrence Erlbaum Associates Inc

Perrachione TK, Del Tufo SN, Winter R, Murtagh J, Cyr A, Chang P, Halverson K, Ghosh SS, Christodoulou JA, Gabrieli JDE (2016) Dysfunction of rapid neural adaptation in dyslexia. Neuron 92:1383-1397

Perrett DI (2012) In your face: the new science of human attraction. Macmillan International Higher Education

Perrett DI, Mistlin AJ, Chitty AJ, Smith PAJ, Potter DD, Broennimann R, Harries MH (1988) Specialized face processing and hemispheric asymmetry in man and monkey: evidence from single unit and reaction time studies. Behav Brain Res 29:245-258

Petersen SE, Fox PT, Posner MI, Mintun M, Raichle ME (1988) Positron emission tomographic studies of the cortical anatomy of single-word processing. Nature 331:585-589

Peterzell DH (1991) On the nonrelationship between spatial frequency and cerebral hemispheric competence. Brain Cogn 15:62-68

Peterzell DH (1997) Hemispheric symmetries in the identification of band-pass filtered letters: reply to Christman et al. (1997). Psychon Bull Rev 4:285-287

Pinel P, Lalanne C, Bourgeron T, Fauchereau F, Poupon C, Artiges E, Le Bihan D, Dehaene-Lambertz G, Dehaene S (2015) Genetic and environmental influences on the visual word form and fusiform face areas. Cereb Cortex 25:2478-2493

Pitcher D, Ungerleider LG (2021) Evidence for a third visual pathway specialized for social perception. Trends Cogn Sci 25:100-110

Pitcher D, Walsh V, Yovel G et al (2007) TMS evidence for the involvement of the right occipital face area in early face processing. Curr Biol 17:1568-1573

Posner M, Carr T (1992) Lexical access and the brain: anatomical constraints on cognitive models of word recognition. Am J Psychol 105:1-26

Price CJ, Devlin JT (2003) The myth of the visual word form area. Neuroimage 19:473-481

Puce A, Allison T, Asgari M, Gore JC, McCarthy G (1996) Differential sensitivity of human visual cortex to faces, letterstrings, and textures: a functional magnetic resonance imaging study. J Neurosci 16:5205-5215

Pyles JA, Verstynen TD, Schneider W, Tarr MJ (2013) Explicating the face perception network with white matter connectivity. PLoS ONE 8(4):e61611
Quek GL, Liu-Shuang J, Goffaux V, Rossion B (2018) Ultra-coarse, single-glance human face detection in a dynamic visual stream. Neuroimage 176:465-476

Rangarajan V, Hermes D, Foster BL, Weiner KS, Jacques C et al (2014) Electrical stimulation of the left and right human fusiform gyrus causes different effects in conscious face perception. J Neurosci 34:12828-12836

Regan D (1966) An effect of stimulus colour on average steady-state potentials evoked in man. Nature 210(5040):1056-1057

Reicher GM (1969) Perceptual recognition as a function of meaningfulness of stimulus material. J Exp Psychol 81:275-280

Richlan F (2012) Developmental dyslexia: dysfunction of a left hemisphere reading network. Front Human Neurosci 6:120. https:// doi.org/10.3389/fnhum.2012.00120

Rekow D, Durand K, Baudouin J-Y, Rossion B, Leleu A (2020) Categorization of objects and faces in the infant brain and its sensitivity to maternal odor: further evidence for the role of intersensory congruency in perceptual development. Cogn Dev 55:100930

Rekow D, Baudouin J-Y, Poncet F, Damon F, Durand K, Schaal B, Rossion B, Leleu A (2021) Odor-driven face pareidolia in the infant brain. Proc Natl Acad Sci USA 118(21):e2014979118

Richlan F (2020) The functional neuroanatomy of developmental dyslexia across languages and writing systems. Front Psychol. https://doi.org/10.3389/fpsyg.2020.00155

Rizzolatti G, Umiltà C, Berlucchi G (1971) Opposite superiorities of the right and left cerebral hemispheres in discriminative reaction time to physiognomical and alphabetical material. Brain 94:431-442

Robertson LC, Lamb MR, Knight RT (1988) Effects of lesions of temporal-parietal junction on perceptual and attentional processing in humans. J Neurosci 8:3757-4376

Robinson AK, Plaut DC, Behrmann M (2017) Word and face processing engage overlapping distributed networks: evidence from RSVP and EEG investigations. J Exp Psychol Gen 146:943

Rosselli M, Ardila A, Matute E, Vélez-Uribe I (2014) Language development across the life span: a neuropsychological/neuroimaging perspective. Neurosci J 2014:585237

Rossion B, Kung C-C, Tarr MJ (2004) Visual expertise with nonface objects leads to competition with the early perceptual processing of faces in the human occipitotemporal cortex. Proc Natl Acad Sci USA 101(40):14521-14526

Rossion B, Collins D, Goffaux V, Curran T (2007) Long-term expertise with artificial objects increases visual competition with early face categorization processes. J Cogn Neurosci 19(3):543-555

Rossion B, Torfs K, Jacques C, Liu-Shuang J (2015) Fast periodic presentation of natural images reveals a robust face-selective electrophysiological response in the human brain. J vis 15(1):18

Rossion B (2008) Picture-plane inversion leads to qualitative changes of face perception. Acta Physiol (oxf) 128(2):274-289

Rossion B (2009) Distinguishing the cause and consequence of face inversion: the perceptual field hypothesis. Acta Physiol (oxf) $132: 300-312$

Rossion B (2013) The composite face illusion: a window to our understanding of holistic face perception. Vis Cogn 121:139-253

Rossion B (2018a) Damasio's error-prosopagnosia with intact withincategory object recognition. J Neuropsychol 12:357-388

Rossion B (2018b) Prosopdysgnosia? What could it tell us about the neural organization of face and object recognition? Cogn Neuropsychol 35:98-101

Rossion B, Jacques C (2011) The N170: understanding the time-course of face perception in the human brain. In: Luck S, Kappenman E (eds) The Oxford handbook of ERP components. Oxford University Press, Oxford, pp 115-142

Rossion B, Taubert J (2019) What can we learn about human individual face recognition from experimental studies in monkeys? Vis Res 157:142-158 
Rossion B, Dricot L, Devolder A, Bodart JM, Crommelinck M, De Gelder B, Zoontjes R (2000) Hemispheric asymmetries for whole-based and part-based face processing in the human fusiform gyrus. J Cogn Neurosci 12:793-802

Rossion B, Joyce CA, Cottrell GW, Tarr MJ (2003) Early lateralization and orientation tuning for face, word, and object processing in the visual cortex. Neuroimage 20(3):1609-1624. https://doi.org/ 10.1016/j.neuroimage.2003.07.010

Rossion B, Dricot L, Goebel R, Busigny T (2011) Holistic face categorization in higher-level cortical visual areas of the normal and prosopagnosic brain: towards a non-hierarchical view of face perception. Front Hum Neurosci 4:225

Rossion B, Hanseeuw B, Dricot L (2012) Defining face perception areas in the human brain: a large-scale factorial fMRI face localizer analysis. Brain Cogn 79(2):138-157. https://doi.org/10. 1016/j.bandc. 2012.01 .001

Rossion B, Retter TL, Liu-Shuang J (2020) Understanding human individuation of unfamiliar faces with oddball fast periodic visual stimulation and electroencephalography. Eur J Neurosci 52:4283-4344

Salmelin R, Service E, Kiesilä P, Uutela K, Salonen O (1996) Impaired visual word processing in dyslexia revealed with magnetoencephalography. Ann Neurol 40:157-162

Sangrigoli S, de Schonen S (2004) Effect of visual experience on face processing: a developmental study of inversion and non-native effects. Dev Sci 7:74-87

Saygin ZM, Osher DE, Norton ES, Youssoufian DA, Beach SD, Feather J, Gaab N, Gabrieli JDE, Kanwisher N (2016) Connectivity precedes function in the development of the visual word form area. Nat Neurosci 19:1250-1255

Scherf KS, Behrmann M, Humphreys K, Luna B (2007) Visual category-selectivity for faces, places and objects emerges along different developmental trajectories. Dev Sci 10(4):F15-F30. https://doi.org/10.1111/j.1467-7687.2007.00595.x

Schiltz C, Rossion B (2006) Faces are represented holistically in the human occipito-temporal cortex. Neuroimage 32(3):1385-1394. https://doi.org/10.1016/j.neuroimage.2006.05.037

Schwarzer G (2000) Development of face processing: the effect of face inversion. Child Dev 71:391-401

Sergent J (1982a) The cerebral balance of power: confrontation or cooperation? J Exp Psychol Hum Percept Perform 8:253-272

Sergent J (1982b) Theoretical and methodological consequences of variations in exposure duration in visual laterality studies. Percept Psychophys 31:451-461

Sergent J (1983) Role of input in visual hemispheric asymmetries. Psychol Bull 93:481-512

Sergent J (1984) An investigation into component and configural processes underlying face perception. Br J Psychol 75:221-242

Sergent J (1985) Influence of input and task factors in hemispheric involvement in face processing. J Exp Psychol Hum Percept Perform 11:253-272

Sergent J (1986) Microgenesis of face perception. In: Ellis HD, Jeeves MA, Newcombe F, Young AM (eds) Aspects of face processing. Martinus Nijhoff, Dordrecht, pp 17-33

Sergent J (1987) Failures to confirm the spatial-frequency hypothesis: fatal blow or healthy complication? Can J Psychol 41:412-428

Sergent J (1988) Face perception and the right hemisphere. In: Weiskrantz L (ed) Thought without language. Oxford University Press ed., Oxford, pp 108-131

Sergent J, Hellige JB (1986) Role of input factors in visual-field asymmetries. Brain Cogn 5(2):174-199

Sergent J, Signoret JL (1992) Varieties of functional deficits in prosopagnosia. Cereb Cortex 2:375-388
Sergent J, Ohta S, MacDonald B (1992) Functional neuroanatomy of face and object processing. A Positron Emission Tomography study. Brain 115(Pt 1):15-36

Sigurdardottir HM, Ívarsson E, Kristinsdóttir K, Kristjánsson Á (2015) Impaired recognition of faces and objects in dyslexia: evidence for ventral stream dysfunction? Neuropsychology 29:739-750

Skeide MA, Kumar U, Mishra RK, Tripathi VN, Guleria A, Singh JP, Eisner F, Huettig F (2017) Learning to read alters corticosubcortical cross-talk in the visual system of illiterates. Sci Adv 3(5): 1602612

Sorensen, TA, Overgaard MS (2018) Prosopagnosia or prosopdysgnosia: facing up to a change of concepts. In: 2018 10th international conference on knowledge and smart technology (KST)

Springer SP, Deutsch G (1981) Left brain, right brain. W. H. Freeman, Francisco

Srebro R (1985) Localization of visually evoked cortical activity in humans. J Physiol 360:233-246

Starrfelt R, Gerlach C (2007) The visual what for area: words and pictures in the left fusiform gyrus. Neuroimage 35(1):334-342

Stevens WD, Kravitz DJ, Peng CS, Tessler MH, Martin A (2017) Privileged functional connectivity between the visual word form area and the language system. J Neurosci 37:5288-5297

Sugden NA, Mohamed-Ali MI, Moulson MC (2014) I spy with my little eye: typical, daily exposure to faces documented from a first-person infant perspective. Dev Psychobiol 56:249-261

Szwed M, Dehaene S, Kleinschmidt A, Eger E, Valabrègue R, Amadon A, Cohen L (2011) Specialization for written words over objects in the visual cortex. Neuroimage 56:330-344

Tan LH, Laird AR, Li K, Fox PT (2005) Neuroanatomical correlates of phonological processing of Chinese characters and alphabetic words: a meta-analysis. Hum Brain Mapp 25:83-91

Tanaka J, Farah MJ (1993) Parts and wholes in face recognition. Quart J Exp Psychol 46A:225-245

Tarkiainen A, Helenius P, Hansen PC, Cornelissen PL, Salmelin R (1999) Dynamics of letter string perception in the human occipitotemporal cortex. Brain 122(Pt 1):2119-2132

Thesen T, McDonald CR, Carlson C, Doyle W, Cash S, Sherfey J, Felsovalyi O, Girard H, Barr W, Devinsky O, Kuzniecky R, Halgren E (2012) Sequential then interactive processing of letters and words in the left fusiform gyrus. Nat Commun 3:1284

Thiebaut De Schotten M, Cohen L, Amemiya E, Braga LW, Dehaene S (2014) Learning to read improves the structure of the arcuate fasciculus. Cereb Cortex 24:989-995

Todorov A (2017) Face value: the irresistible influence of first impressions. Princeton University Press

Tranel D, Vianna E, Manzel K, Damasio H, Grabowski T (2009) Neuroanatomical correlates of the Benton Facial Recognition Test and judgment of Line Orientation Test. J Clin Exp Neuropsychol 31:219-233

Tsao DY, Moeller S, Freiwald WA (2008) Comparing face patch systems in macaques and humans. Proc Natl Acad Sci USA 105:19514-19519

Turati C, Simion F (2002) Newborns' recognition of changing and unchanging aspects of schematic faces. J Exp Child Psychol 83:239-261

Turkeltaub PE, Gareau L, Flowers DL, Zeffiro TA, Eden GF (2003) Development of neural mechanisms for reading. Nat Neurosci 6(7):767-773

Tzavaras A, Merienne L, Masure MC (1973) Prosopagnosie, amnésie et troubles du langage par lésion temporale gauche chez un sujet gaucher. Encephale 62:382-394

Tzourio-Mazoyer N, De Schonen S, Crivello F, Reutter B, Aujard Y, Mazoyer B (2002) Neural correlates of woman face processing by 2-month-old infants. Neuroimage 15:454-461

Van Kleeck MH (1989) Hemispheric differences in global versus local processing of hierarchical visual stimuli by normal subjects: new 
data and a meta-analysis of previous studies. Neuropsychologia 27:1165-1178

Van Belle G, de Graef P, Verfaillie K, Busigny T, Rossion B (2010) Whole not hole: expert face recognition requires holistic perception. Neuropsychologia 48:2609-2620

Van Paridon J, Ostarek M, Arunkumar M, Huettig F (2020) Does neuronal recycling result in destructive competition? The influence of learning to read on the recognition of faces. Psychol Sci 32:459-465

Van der Haegen L, Brysbaert M (2018) The relationship between behavioral language laterality, face laterality and language performance in left-handers. PLoS ONE 13:1-22

Van der Haegen L, Cai Q, Brysbaert M (2012) Colateralization of Broca's area and the visual word form area in left-handers: fMRI evidence. Brain Lang 122:171-178

Ventura P, Fernandes T, Cohen L, Morais J, Kolinsky R, Dehaene S (2013) Literacy acquisition reduces the influence of automatic holistic processing of faces and houses. Neurosci Lett 554:105109. https://doi.org/10.1016/j.neulet.2013.08.068

Vermeire BA, Hamilton CR (1998) Inversion effect for faces in splitbrain monkeys. Neuropsychology 36:1003-1014

Vermeire BA, Hamilton CR, Erdmann AL (1998) Right-hemispheric superiority in split-brain monkeys for learning and remembering facial discriminations. Behav Neurosci 112(5):1048-1061

Vettori S, Dzhelyova M, Van der Donck S, Jacques C, Steyaert J, Rossion B, Boets B (2019) Reduced neural sensitivity to rapid individual face discrimination in autism spectrum disorder. Neuroimage Clin 21:101613

Vidal JR, Ossandón T, Jerbi K, Dalal SS, Minotti L, Ryvlin P, Kahane P, Lachaux J-P (2010) Category-specific visual responses: an intracranial study comparing gamma, beta, alpha, and ERP response selectivity. Front Hum Neurosci 4:195. https://doi.org/ 10.3389/fnhum.2010.00195

Vinckier F, Dehaene S, Jobert A, Dubus JP, Sigman M, Cohen L (2007) Hierarchical coding of letter strings in the ventral stream: dissecting the inner organization of the visual word-form system. Neuron 55:143-156

Vogel AC, Petersen SE, Schlaggar B (2012) The left occipitotemporal cortex does not show preferential activity for words. Cereb Cortex 22:2715-2732

Willems RM, Peelen MV, Hagoort P (2010) Cerebral lateralization of face-selective and body-selective visual areas depends on handedness. Cereb Cortex 20:1719-1725

Wong ACN, Wong YK, Lui KFH, Ng TYK, Ngan VSH (2019) Sensitivity to configural information and expertise in visual word recognition. J Exp Psychol Hum Percept Perform 45:82-99
Wright H, Wardlaw J, Young AW, Zeman A (2006) Prosopagnosia following nonconvulsive status epilepticus associated with a left fusiform gyrus malformation. Epilepsy Behav 9:197-203

Wu C, Ho MR, Chen SA (2012) NeuroImage-a meta-analysis of fMRI studies on Chinese orthographic, phonological, and semantic processing. NeuroImage 63:381-391

Yan X, Goffaux V, Rossion B (2020) Coarse-to-fine(r) automatic familiar face recognition in the human brain. Cereb Cortex.

Yin RK (1969) Looking at upside-down faces. J Exp Psychol 81:141-145

Yoncheva YN, Blau VC, Maurer U, McCandliss BD (2010) Attentional focus during learning impacts N170 ERP responses to an artificial script. Dev Neuropsychol 35(4):423-445

Yoncheva YN, Wise J, McCandliss B (2015) Hemispheric specialization for visual words is shaped by attention to sublexical units during initial learning. Brain Lang 145:23-33

Young AW, Hellawell D, Hay DC (1987) Configurational information in face perception. Perception 16:747-759

Yovel G (2016) Neural and cognitive face-selective markers: an integrative review. Neuropsychologia 83:5-13

Yovel G, Levy J, Grabowecky M, Paller KAJ (2003) Neural correlates of the left-visual-field superiority in face perception appear at multiple stages of face processing. J Cogn Neurosci 15:462-474

Yovel G, Tambini A, Brandman T (2008) The asymmetry of the fusiform face area is a stable individual characteristic that underlies the left-visual-field superiority for faces. Neuropsychologia 46:3061-3068

Zangenehpour S, Chaudhuri A (2005) Patchy organization and asymmetric distribution of the neural correlates of face processing in monkey inferotemporal cortex. Curr Biol 15(11):993-1005

Zhang L, Tan A, Schreiner C et al (2003) Topography and synaptic shaping of direction selectivity in primary auditory cortex. Nature 424:201-205

Zhang MX, Jiang T, Mei LL, Yang HM, Chen CS, Xue G, Dong Q (2011) It's a word: early electrophysiological response to the character likeness of pictographs. Psychophysiology 48:950-959

Zhen Z, Yang Z, Huang L, Kong XZ, Wang X, Dang X, Huang Y, Song Y, Liu J (2015) Quantifying interindividual variability and asymmetry of face-selective regions: a probabilistic functional atlas. Neuroimage 113:13-25

Publisher's Note Springer Nature remains neutral with regard to jurisdictional claims in published maps and institutional affiliations. 


\section{Terms and Conditions}

Springer Nature journal content, brought to you courtesy of Springer Nature Customer Service Center GmbH ("Springer Nature").

Springer Nature supports a reasonable amount of sharing of research papers by authors, subscribers and authorised users ("Users"), for smallscale personal, non-commercial use provided that all copyright, trade and service marks and other proprietary notices are maintained. By accessing, sharing, receiving or otherwise using the Springer Nature journal content you agree to these terms of use ("Terms"). For these purposes, Springer Nature considers academic use (by researchers and students) to be non-commercial.

These Terms are supplementary and will apply in addition to any applicable website terms and conditions, a relevant site licence or a personal subscription. These Terms will prevail over any conflict or ambiguity with regards to the relevant terms, a site licence or a personal subscription (to the extent of the conflict or ambiguity only). For Creative Commons-licensed articles, the terms of the Creative Commons license used will apply.

We collect and use personal data to provide access to the Springer Nature journal content. We may also use these personal data internally within ResearchGate and Springer Nature and as agreed share it, in an anonymised way, for purposes of tracking, analysis and reporting. We will not otherwise disclose your personal data outside the ResearchGate or the Springer Nature group of companies unless we have your permission as detailed in the Privacy Policy.

While Users may use the Springer Nature journal content for small scale, personal non-commercial use, it is important to note that Users may not:

1. use such content for the purpose of providing other users with access on a regular or large scale basis or as a means to circumvent access control;

2. use such content where to do so would be considered a criminal or statutory offence in any jurisdiction, or gives rise to civil liability, or is otherwise unlawful;

3. falsely or misleadingly imply or suggest endorsement, approval, sponsorship, or association unless explicitly agreed to by Springer Nature in writing;

4. use bots or other automated methods to access the content or redirect messages

5. override any security feature or exclusionary protocol; or

6. share the content in order to create substitute for Springer Nature products or services or a systematic database of Springer Nature journal content.

In line with the restriction against commercial use, Springer Nature does not permit the creation of a product or service that creates revenue, royalties, rent or income from our content or its inclusion as part of a paid for service or for other commercial gain. Springer Nature journal content cannot be used for inter-library loans and librarians may not upload Springer Nature journal content on a large scale into their, or any other, institutional repository.

These terms of use are reviewed regularly and may be amended at any time. Springer Nature is not obligated to publish any information or content on this website and may remove it or features or functionality at our sole discretion, at any time with or without notice. Springer Nature may revoke this licence to you at any time and remove access to any copies of the Springer Nature journal content which have been saved.

To the fullest extent permitted by law, Springer Nature makes no warranties, representations or guarantees to Users, either express or implied with respect to the Springer nature journal content and all parties disclaim and waive any implied warranties or warranties imposed by law, including merchantability or fitness for any particular purpose.

Please note that these rights do not automatically extend to content, data or other material published by Springer Nature that may be licensed from third parties.

If you would like to use or distribute our Springer Nature journal content to a wider audience or on a regular basis or in any other manner not expressly permitted by these Terms, please contact Springer Nature at

onlineservice@springernature.com 